\title{
Presupposed ignorance and exhaustification: how scalar implicatures and presuppositions interact
}

\author{
Benjamin Spector $^{1}$ - Yasutada Sudo $^{2}$ (D)
}

Published online: 30 May 2017

(C) The Author(s) 2017. This article is an open access publication

\begin{abstract}
We investigate the interactions between scalar implicatures and presuppositions in sentences containing both a scalar item and presupposition trigger. We first critically discuss Gajewski and Sharvit's previous approach. We then closely examine two ways of integrating an exhaustivity-based theory of scalar implicatures with a trivalent approach to presuppositions. The empirical side of our discussion focuses on two novel observations: (i) the interactions between prosody and monotonicity, and (ii) what we call presupposed ignorance. In order to account for these observations, our final proposal relies on two mechanisms of scalar strengthening, the Presupposed Ignorance Principle and an exhaustivity operator which lets the presuppositions of negated alternatives project.
\end{abstract}

\footnotetext{
The authors' names are alphabetically ordered.

The present work has greatly benefitted from discussions with a number of colleagues, especially, Klaus Abels, Sam Alxatib, Emmanuel Chemla, Luka Crnič, Danny Fox, Nathan Klinedinst, Todor Koev,

Clemens Mayr, Andreea Nicolae, Rick Nouwen, Jacopo Romoli, Uli Sauerland, Philippe Schlenker, Yael Sharvit, and Raj Singh. We also thank the audiences at University College London, Queen Mary, University of London, Utrecht University, ZAS, LFRG at MIT, the Semantics Research Seminar at Keio University, and Sinn und Bedeutung 19 at Georg August University at Göttingen for their feedback on earlier versions of the present work.

Benjamin Spector and Yasutada Sudo acknowledge support from the Agence Nationale de la Recherche (Grants ANR-10-LABX-0087 IEC, ANR-10-IDEX-0001-02 PSL) and the European Research Council (ERC Grant Agreement No. 324115-FRONTSEM, recipient: Philippe Schlenker). Benjamin Spector also received support from an additional ANR Grant (ANR-14-CE30-0010-01 TriLogMean).

$\bowtie$ Yasutada Sudo y.sudo@ucl.ac.uk

1 Département d'études cognitives, Institut Jean Nicod (CNRS-ENS-EHESS), Ecole Normale Supérieure - PSL Research University, Paris, France

2 University College London, 2 Wakefield St., London E1 1DE, UK
} 
Keywords Scalar implicature · Presupposition · Exhaustification ·

Presupposed ignorance

\section{Introduction}

We investigate the interactions between scalar implicatures and presuppositions in sentences like (1).

(1) John is aware that some of the students smoke.

This sentence contains a factive predicate, aware, and a scalar item, some, in its scope. ${ }^{1}$ Both theoretically and empirically, it is not immediately clear what kind of scalar inference (1) triggers and this is exactly the question that we will attempt to answer in the present paper.

Despite the growing interests in both scalar implicature and presupposition in formal linguistics and neighboring fields, cases like (1) have scarcely been discussed in the literature, with the notable exceptions of Sharvit and Gajewski (2008) and Gajewski and Sharvit (2012). ${ }^{2}$ Gajewski and Sharvit mainly discuss scalar inferences of sentences containing a negative factive predicate like unaware as in (2). ${ }^{3}$

\footnotetext{
${ }^{1}$ We follow the standard literature in assuming that aware has a lexically specified factive presupposition that the complement clause is true. Although one might be skeptical about this assumption, our main results do not rely on this particular lexical item and hold with other kinds of presupposition triggers. In fact, we will see some examples with the additive particle too, the implicative verb forget, etc. as we go along. We use aware here, as it makes it easy to construct minimal pairs with its negative counterpart unaware.

${ }^{2}$ Besides Gajewski and Sharvit's work, Chemla (2009) should also be mentioned here. Chemla offers a unified theory of presupposition projection and scalar implicatures, but does not focus much on their interactions in single sentences. Nevertheless he briefly discusses the predictions of his approach for sentences such as (1), in relation with Gajewski and Sharvit's proposal. Putting aside the details, Chemla's prediction for this particular case is that (2) presupposes that some but not all of the students smoke and also that John is aware that some of the students smoke. In other cases, Chemla's approach makes predictions which are crucially distinct from both Gajewski and Sharvit's theory and our own approach. We do not go into the details of Chemla's approach in this paper, as it would involve reviewing Chemla's full framework for scalar implicatures and presuppositions, even though we point out in fn.19 that a version of Chemla's approach would make predictions that are essentially identical to the theory presented in Sect. 4.

Chierchia's (2004) and Russell (2006) briefly mention sentences like (1). Assuming that (1) presupposes that not all of the students smoke, Chierchia states in passing that his theory derives this inference, but Russell correctly points out that Chierchia's empirical assumptions are not justified, a point we will return to in great detail. Russell himself suggests a pragmatic analysis of scalar inferences associated with sentences like (1), but does not offer a theory that is detailed enough. For this reason we will not delve into Russell's idea in the present paper.

Horn (1997) and Potts (2015) are survey articles covering both scalar implicature and presupposition, but they only discuss these inferences separately with no mention of their interactions. Classically, Gazdar (1979) and van der Sandt (1988) examined the interactions of the two kinds of inferences in the context of presupposition projection, but their perspectives are different from ours, and their theories have no direct bearings on the issues we are concerned with.

${ }^{3}$ Gajewski and Sharvit use sorry, instead of unaware, and focus on the presupposition that the attitude holder believes that the complement clause is true. This is immaterial to our purposes here, as what crucially matters is the monotonicity of the presupposition (and the assertion). Importantly, presupposition triggers like discover, which has a positive factive presupposition and a negative presupposition that the subject was not aware of the relevant fact before the discovery, pose a potential challenge to our final theory. We will discuss this issue in Sect. 6.3.
} 
(2) John is unaware that some of the students smoke.

Briefly put, Gajewski and Sharvit observe that (2) has a reading where the presupposition has a scalar implicature, but the assertion does not, which we take as the starting point of our discussion.

Our main goal here is to closely examine scalar inferences that sentences like (1) and (2) may have, and offer a novel theoretical view on the interactions between scalar implicatures and presuppositions. We will discuss three theories, namely, (i) Gajewski and Sharvit's theory, (ii) a natural extension of one common approach to scalar implicatures to a trivalent framework, and (iii) our own theory, based on an interaction between another natural extension of this approach to a trivalent framework and a new, sui generis principle. Although the first two theories have some appealing features, we point out that they fall short of accounting for certain empirical facts. In particular, we make observations that reveal two novel empirical aspects of the present phenomenon that (i) and (ii) fail to capture, namely, a) the interaction between prosody and monotonicity, and b) what we call presupposed ignorance. Let us briefly mention the main empirical data illustrating these two phenomena here.

Prosodic effects in the sentences like (1) and (2) have been almost completely neglected, but as the following examples demonstrate, prosody makes it clear that there is a crucial difference between positive sentences like (1) and negative sentences like (2). Specifically, the scalar item can be naturally given prosodic prominence (indicated by SMALL CAPS throughout the paper) in the positive example (1), as in (3-a), and then can give a rise to the inference that all of the students smoke but that John is unaware of that fact. In the negative counterpart (2), by contrast, prosodic prominence on the scalar item is not very natural, as in (3-b).

a. John is aware that SOME of the students smoke.

b. \#John is unaware that SOME of the students smoke.

As we will see, this contrast remains puzzling for the first two theories we will consider.

The second phenomenon we will discuss, presupposed ignorance, has also gone unnoticed previously. We illustrate it with the following example.

(4) Mary will go to Yale. \#John, too, will go to Yale or Harvard.

As we will explain in more detail later, given standard assumptions about the meaning of too, it is not obvious why this example should be infelicitous. Notice in particular that the additive presupposition triggered by too should be satisfied by what is asserted by the first sentence, since it provides an antecedent, namely Mary, who is ascribed the property of going to Yale, which entails going to Yale or Harvard. We will claim that the anomaly of the second sentence of (4) is caused by an additional inference to the effect that it is not presupposed that Mary will go to Yale, which we call a presupposed ignorance inference. We will put forward an account of presupposed ignorance using what we call the Presupposed Ignorance Principle (PIP). 


\section{Presupposed Ignorance Principle:}

Let $p$ be the presupposition of sentence $\phi$. If $\phi$ has an alternative $\psi$ presupposing $q$ and $q$ asymmetrically entails $p, \phi$ is infelicitous in context $c$ if $q$ is satisfied in $c$.

Putting the details aside for the moment, the PIP forces a use of the alternative with the strongest presupposition that is satisfied in the context of utterance. ${ }^{4}$ We will show that the PIP can be used to derive Gajewski and Sharvit's observation regarding (2) as a special case.

We will also see, however, that the PIP by itself makes wrong predictions for sentences like (1) whose assertion and presupposition are both positive. In order to solve this problem, we will posit a second mechanism of scalar strengthening, namely exhaustification, which can be captured in terms of an exhaustivity operator (ExH) whose meaning is akin to only. Although exhaustivity operators have been employed by many recent studies to account for various types of scalar inferences (Groenendijk and Stokhof 1984; Chierchia 2006; Chierchia et al. 2012; Fox 2007; Ivlieva 2013; Meyer 2013; Romoli 2012; van Rooij and Schulz 2004; Spector 2003, 2007), its presuppositional properties have not been given enough attention. We will show that the assumption that EXH is a presupposition hole with respect to negated alternatives offers an explanation for the interactions between prosody and monotonicity illustrated by (4) with very natural auxiliary assumptions.

Thus, according to our theory, there are two separate scalar mechanisms responsible for the interactions between scalar implicatures and presuppositions, namely, the PIP and the exhaustivity operator EXH.

We would like to stress that our claims in this paper are for the most part orthogonal to the debate between 'pragmatic' and 'grammatical' approaches to scalar implicatures. Even though we make use of exhaustivity operators for the sake of explicitness and clarity, for the most part we will discuss readings that we can derive by applying an exhaustivity operator to whole sentences, i.e. cases that do not involve so-called 'embedded implicatures' (see however Sect. 6.4). For this reason, we do not exclude at all the possibility that our proposal might be, to a certain extent at least, recast in terms of a pragmatic approach to scalar implicatures.

The structure of the paper is as follows. In Sect. 2, We will first critically examine Gajewski and Sharvit's grammatical theory. Then in Sect. 3 we will investigate ways in which the presuppositional properties of EXH could be implemented in a trivalent approach to presupposition. We will pursue one of these ways in Sect. 4, and point out empirical shortcomings. Section 5 is devoted to our novel analysis, which postulates two scalar strengthening mechanisms, EXH and the PIP. After addressing some further issues in Sect. 6, we will conclude in Sect. 7.

\footnotetext{
4 The PIP bears noticeable resemblance to the principle of Maximize Presupposition (MP) proposed by Heim (1991). In fact, the PIP could be seen as a generalized version of MP. Importantly, however, MP, as standardly formalized, cannot be used to derive presupposed ignorance inferences. We will come back to this briefly in Sect. 5.1 and discuss their differences in detail in the Appendix.
} 


\section{Gajewski and Sharvit's account}

Sharvit and Gajewski (2008) and Gajewski and Sharvit (2012) make an important observation regarding sentences like (2), repeated below, that involve negative factive predicates (see also Simons 2006 for relevant discussion). Here and throughout, we will only be concerned with the surface scope reading, i.e. the non-specific reading of some. ${ }^{5}$

(2) John is unaware that some of the students smoke.

In short, Gajewski and Sharvit point out that (2) has a scalar implicature in the presupposition but not in the assertion. This reading can be represented as (6), where $B_{j}$ means 'John believes that' 6

a. ASSERTION: $\neg B_{j}(\exists x \in \operatorname{student}[\operatorname{smoke}(x)])$

b. PRESUPPOSITION: $[\exists x \in \operatorname{student}[\operatorname{smoke}(x)]] \wedge[\neg \forall x \in \operatorname{student}[\operatorname{smoke}(x)]]$

As expected from this analysis, the sentence (2) is indeed infelicitous in contexts where it is commonly known that all of the students smoke. .,8 $^{\text {. }}$

(7) CONTEXT: John wonders if any students smoke. We know all do.

\#John is unaware that some of the students smoke.

5 If the reader finds it difficult to disregard the wide scope reading of some, please consider the versions of the examples below where some is replaced with most, which does not allow such a wide scope reading, but still generates a scalar implicature relative to all.

6 We are not concerned here with the detailed meaning of unaware, and simply analyze its assertion to mean 'not believe', and its presupposition to be merely factive. This is arguably too simplistic, especially with respect to the so-called Gettier problem (Gettier 1963), but it is sufficient for our purposes.

7 Note that even helps in this context with a stress on some:

(i) CONTEXT: John wonders if any students smoke. We know all do.

John is even unaware that SOME of the students smoke.

We will come back to this observation in fn.28.

8 It is also expected, given the analysis in (6), that the sentence should be infelicitous in contexts where it is not commonly known that not all of the students smoke. However, the judgments are not as clear as for (7). Consider (i), for example.

(i) CONTEXT: We know some of the students are smokers, but are wondering if all are. We are thinking of asking John, but then are told:

(?) John is unaware that some of the students smoke.

One way to think about (i) that is compatible with the reading in (6) is in terms of scalar implicature 'cancellation'. Scalar implicatures are generally optional, and it is not inconceivable that the context given here facilitates the non-derivation of the scalar inference altogether, which results in a presupposition that is merely existential and hence is compatible with the context given here. Although this raises further questions, e.g. what contextual factors make it easier not to compute the scalar implicature in (i) than in (7), we think this data point does not necessarily challenge Gajewski and Sharvit's analysis. As we will see later, our analysis accounts for this observation more straightforwardly. 
This is more clearly seen with an example like (8) where the scalar implicature in the presupposition conflicts with the world knowledge that all natural languages have pronouns.

(8) \#John is unaware that some of the natural languages have pronouns.

Crucially, the reading in question is different from the reading that would arise if the scalar implicature were computed in the scope of unaware. This reading for (2) would be paraphrased by (9).

(9) John is unaware that some but not all of the students smoke.

a. ASSERTION: $\neg B_{j}([\exists x \in \operatorname{student}[\operatorname{smoke}(x)]] \wedge[\neg \forall x \in \operatorname{student}[\operatorname{smoke}$ $(x)]])$

b. PRESUPPOSITION: $[\exists x \in \operatorname{student}[\operatorname{smoke}(x)]] \wedge[\neg \forall x \in \operatorname{student}[\operatorname{smoke}$ $(x)]]$

This reading, if possible at all for (2), has the same presupposition as the reading we are after but its assertive meaning is weaker. Thus the two readings are truth-conditionally distinguishable. Specifically, there are situations that make the reading in (6) false and the reading in (9) true, as demonstrated by the dialogue in (10).

(10) CONTEXT: We know that only some of the students smoke.

A: John has been in this department for a year now, but he is unaware that some of the students smoke.

B: That's not true! Quite the contrary, he wrongly thinks that all do.

In this example, the way (10-B) understands the assertive meaning of the sentence in bold face is not (9), which would be inconsistent with the second sentence of (10-B). In contrast with this, the reading hypothesized in (6) makes this dialogue coherent.

As Gajewski and Sharvit argue, the reading in (6) poses an interesting theoretical question: How does a scalar implicature arise just in the presupposition without also arising in the assertive meaning? ${ }^{9}$ This is part of the main question we will be concerned with in this paper. We will first review Gajewski and Sharvit's take on the issue, which is based on Chierchia's (2004) theory of scalar implicature computation, and then point out two empirical problems for it. ${ }^{10}$

\footnotetext{
9 As Gajewski and Sharvit (2012) note, the reading (6) cannot be accounted for by Maximize Presupposition (Heim 1991; Percus 2006; Sauerland 2008; Singh 2011; Schlenker 2012). See Appendix for details.

10 It should be emphasized that we focus exclusively on one aspect of Gajewski and Sharvit's work here. They raise two other sets of data as support for the grammatical view of scalar implicatures, for which they do not use Chierchia's (2004) theory. We have nothing interesting to say about these phenomena in the present paper.
} 


\subsection{Gajewski and Sharvit's analysis}

According to Chierchia (2004), scalar implicatures are introduced when scalar items are computed in the course of compositional semantic computation. For an illustration, consider the following simple sentence with a scalar item some.

(11) Some of the students smoke.

In order to simplify the exposition we will not present the technical details of Chierchia's theory, but here is the core idea behind it. Chierchia postulates the compositional rule of Strong Application, which introduces the negation of the meaning of 'all of the students smoke', when applying the meaning of some of the students to that of smoke, as illustrated in (12).

STRONG.APPLICATION(some of the students, smoke) $=\llbracket$ some of the students $\rrbracket(\llbracket$ smoke $\rrbracket) \wedge \neg \llbracket$ all of the students $\rrbracket(\llbracket$ smoke $\rrbracket)$

Strong Application also has a function of removing scalar implicatures in decreasing contexts. For example, when the computation hits a decreasing operator like doubt, it removes the scalar implicature of its argument. ${ }^{11}$ For instance, when (12) is embedded under doubt, as in (13), it loses the scalar implicature that not all of the students smoke.

(13) I doubt that some of the students smoke.

(14) STRONG.APPLICATION(doubt, some of the students smoke)

$=\llbracket$ doubt $\rrbracket(\llbracket$ some of the students smoke $\rrbracket)$

$(\neq \llbracket$ doubt $\rrbracket($ STRONG.APPLICATION(some of the students, smoke $)))$

In order to account for the reading in (6) above, Gajewski and Sharvit propose the following modification to Chierchia's theory: Strong Application computes scalar implicatures in the assertive meaning and presupposition separately. This necessitates a two-dimensional theory of presupposition in the style of Karttunen and Peters (1979). Let's look at the example (2), repeated here, to see how it works.

John is unaware that some of the students smoke.

When the embedded sentence is computed, Strong Application introduces a scalar implicature that not all of the students smoke, as we saw above. Now, we compute the meaning of the matrix material. Importantly, unaware is decreasing in the assertion but increasing in the presupposition. According to Gajewski and Sharvit's proposal, these two dimensions of meaning are dealt with independently, and the scalar implicature that not all of the students smoke gets suspended in the assertion, just as in the case of (13) above, while in the presupposition it stays intact. Consequently, we obtain the following reading, as desired.

a. ASSERTION: $\neg B_{j}(\exists x \in \operatorname{student}[\operatorname{smoke}(x)])$

\footnotetext{
11 Strong Application also introduces an 'indirect implicature', if any, e.g. John doubts that all of the students smoke has a (indirect) scalar implicature that John does not doubt that some of the students smoke. Indirect implicatures are orthogonal to the discussion here.
} 
b. PRESUPPOSITION: $[\exists x \in \operatorname{student}[\operatorname{smoke}(x)]] \wedge[\neg \forall x \in \operatorname{student}[\operatorname{smoke}(x)]]$

As we have just seen, Gajewski and Sharvit's analysis nicely accounts for the intended reading of (2). However, this analysis has several empirical shortcomings.

\subsection{Problem 1: Positive versus negative}

We observe that the positive version of (2), namely (1), is felicitous in certain contexts where it is common knowledge that all of the students smoke, in contrast with (2) (see Russell 2006; Simons 2006 for related remarks). ${ }^{12}$ Concretely, consider the sentence put in the context in (15):

CONTEXT: We know that all of the students smoke.

A: John has absolutely no idea how rampant smoking is among the professors and students.

B: But he is aware that some of the students smoke.

$\mathrm{B}^{\prime}$ \#Indeed, he is unaware that some of the students smoke.

Crucially, there is a contrast between (15-B) and (15- $\left.\mathrm{B}^{\prime}\right)$, which indicates that the presupposition of (15-B) is not strengthened into 'Some but not all of the students smoke', unlike what is presumably going on with $\left(15-\mathrm{B}^{\prime}\right)$. This asymmetry is unexpected under Gajewski and Sharvit's view, even if it is granted that scalar implicature computation is optional. The presupposition tends to be strengthened in the case of $(2) /\left(15-B^{\prime}\right)$ in a way that we do not observe for its positive counterpart (1)/(15-B).

In addition, it should be noticed that (15-B) does give rise to a scalar inference in the assertion that John is not aware that all of the students smoke. Thus, it seems that $(1) /(15-\mathrm{B})$ does give rise to a scalar implicature in the assertion but not in the presupposition.

Incidentally the relevant reading of $(1) /(15-\mathrm{B})$ is distinct from the one predicted with an embedded scalar implicature, which is paraphrased by (16).

John is aware that some but not all of the students smoke.

a. ASSERTED: $B_{j}(\exists x \in \operatorname{student}[\operatorname{smoke}(x)] \wedge \neg \forall x \in \operatorname{student}[\operatorname{smoke}(x)])$

b. PRESUPPOSED: $[\exists x \in \operatorname{student}[\operatorname{smoke}(x)]] \wedge[\neg \forall x \in \operatorname{student}[\operatorname{smoke}(x)]]$

We remain neutral with respect to the availability of this reading, but crucially, it would be infelicitous in the context of (15), as it presupposes that not all of the students smoke.

In summary, the contrast between the positive and negative sentences demonstrated in (15) is problematic for Gajewski and Sharvit: they predict that the positive sentence in (1) has the same presupposition as its negative counterpart (2), since their presup-

\footnotetext{
12 Sharvit and Gajewski (2008) and Gajewski and Sharvit (2012) discuss sentences containing the presuppositional attitude predicate discover, which is increasing in the assertion, but their main concern is its decreasing presupposition that the attitude holder was not aware of the truth of the complement clause before the event time. Our argument here has to do with meanings that are increasing in both assertion and presupposition. However, as already noted in fn.3, the non-monotonicity of the presupposition of discover actually poses a potential problem to our final theory. We will discuss this issue in Sect. 6.3.
} 
positions are the same, and hence both of them should be infelicitous in the above context. ${ }^{13}$ Moreover, given that both the assertion and presupposition are increasing in the case of (1), they predict that (1) has a locally computed scalar inference in both the assertion and presupposition, making it synonymous to (16) (again, we remain agnostic as to whether this reading is available).

This problem reveals that the monotonicity properties of the assertive meaning (e.g. aware vs. unaware) matter for the scalar inference in the presupposition. Gajewski and Sharvit's theory fails to account for this, because it computes scalar implicatures in the two dimensions of meaning completely separately. The analysis we will examine in the next section improves on this aspect by requiring scalar implicature computation to simultaneously refer to the two kinds of meaning.

At this point, we would like to make some remarks on (1) that will be of importance in the discussion to follow. Firstly, we observe that the sentence in the context given in (15) is naturally pronounced with a focal stress on the scalar item some, as in (17).

John is aware that SOME of the students smoke.

As we will discuss further, stress has important interpretive effects in the sentences we are after, and should be properly controlled in assessing judgments. We invite the reader to pay attention to the stress pattern in the examples to follow.

Secondly, we note at this point that the meaning of (17) is reminiscent of the reading that obtains with only with a focal stress on the scalar item.

John is only aware that SOME of the students came.

We believe that the use of only often makes the judgments sharper (possibly by eliminating certain other readings), and thus is useful in making the point clearer. Also the (near) synonymy of (17) and (18) is of some theoretical importance, as we will discuss in more detail in Sect. 4.

While the problem we have just pointed out is the most important one, there is another empirical problem that Gajewski and Sharvit's theory runs into.

\subsection{Problem 2: Non-local scalar implicatures}

Since Gajewski and Sharvit's theory is built upon Chierchia's (2004) theory of scalar implicature computation, it inherits the following problem: Chierchia's theory is strictly localist in the sense that it only generates implicatures at the most local positions (putting aside 'indirect implicatures' introduced in downward entailing contexts), but there are cases where the scalar implicature needs to be computed at a non-local position above a certain operator, a problem pointed out by Simons (2006) and Chierchia (2006). For example, consider (19) (under the surface scope reading).

$$
\text { John is required to do a few push-ups. }
$$

\footnotetext{
13 As far as we can, Chemla (2009) runs into the same problem here. There is a version of Chemla's approach, however, which would yield results similar to our proposal in Sect. 4. See fn.19 for details.
} 
This sentence is natural to describe the following scenario: the requirement is that John do at least five push-ups (and five push-ups count as a few push-ups), but he is allowed to do as many as he wants. Crucially, an utterance of (19) in this context has a scalar inference to the effect that John is not required to do many push-ups. In other words, the scalar implicature is computed above required with the relevant scale being $\langle$ a few, many $\rangle$. However, the only reading that Chierchia's (2004) theory is able to generate for (19) is the following, which would be false in this context (and it is not as readily available, if available at all).

(20) John's requirement is that he should do a few but not many push-ups, i.e. he is required not to do many push-ups.

An analogous problem arises for Gajewski and Sharvit with a sentence like (21), which contains the implicative verb forget as a presupposition trigger.

John forgot to do a few push-ups.

Under the most natural reading, the presupposition of (21) is essentially identical to the meaning of (19) above with the scalar inference, i.e. John was required to do a few push-ups but was not required to do many push-ups. However, due to the strictly local nature of scalar implicature computation, Gajewski and Sharvit can only derive (20) as the presupposition for (21). This predicted reading seems to be extremely hard to obtain, if available at all. ${ }^{14}$

It should be mentioned here that Gajewski and Sharvit express a reserved attitude towards Chierchia's (2004) theory of scalar implicature computation, and do not seem to fully endorse it. One could actually imagine a theory in which, like in Gajewski and Sharvit's, a strengthening mechanism applies in parallel in the assertive dimension and in the presuppositional dimension, but where the underlying strengthening mechanism would not give rise to the undesirable prediction that Gajewski and Sharvit's approach does for this specific case. One motivation for Gajewski and Sharvit's choice to build on Chierchia (2004) is their claim that approaches based on EXH cannot account for the relevant facts. In the next sections, however, we will demonstrate that this is not the case: there is a reasonable definition of EXH which allows it to explicate the core data, and the resulting analysis actually fares better than Gajewski and Sharvit's theory based on Chierchia's.

\section{Exhaustivity in a trivalent setting}

Theories of scalar implicatures are usually expressed within a classical, bivalent semantics where every sentence is either true or false. This is fine insofar as presuppositions are not relevant. Many theories of presupposition adopt a richer, trivalent semantics where presupposition failure corresponds to a third truth-value, the 'undefined' truth-value, which we refer to by \# (see, among many others, Peters 1979; Beaver and Krahmer 2001; Fox 2008; George 2008). We will closely examine two

$\overline{14}$ Note that Chemla (2009) makes the desired prediction in this case. 
ways to reconcile standard theories of scalar implicatures and trivalent semantics for presupposition. ${ }^{15}$

As we will see in more detail below, formally explicit accounts of scalar implicatures make use of logical notions such as consistency, entailment and negation. Since there are multiple ways to define these notions within a trivalent framework, decisions have to be made about which definitions to use. We will see below that two different, a priori sensible decisions about the notion of innocent exclusion (see immediately below) and the negation used to negate alternatives lead to different empirical predictions.

We will frame this investigation in terms of a covert exhaustivity operator EXH (Groenendijk and Stokhof 1984; Chierchia 2006; Chierchia et al. 2012; Fox 2007; van Rooij and Schulz 2004; Spector 2003, 2007), but it should be emphasized that we do so, to a certain extent, for expository reasons, that is, to highlight the difference between two distinct ways of adapting theories of scalar implicatures to a trivalent system, on the basis of an explicit theory of scalar implicature computation. In particular, we do not exclude that the ideas presented in the next section might be alternatively cashed out in Neo-Gricean terms (Sauerland 2004; Spector 2003, 2007; Geurts 2010), although a precise formulation of such an alternative is not offered here.

Let us now be more specific. Anticipating the discussion on examples containing disjunction, we will adopt Fox's (2007) notion of Innocent Exclusion and define the bivalent version of EXH as follows. $\operatorname{Alt}(\phi)$ is the set of alternatives to $\phi$.

$$
\begin{aligned}
& \text { a. } \llbracket \operatorname{EXH}_{A l t(\phi)} \phi \rrbracket(w)=1 \text { iff } \llbracket \phi \rrbracket(w)=1 \wedge \forall \psi \in \operatorname{IE}(\phi, \operatorname{Alt}(\phi))[\llbracket \psi \rrbracket(w) \\
& \neq 1] \\
& \text { b. IE } \left.(\phi, A):=\bigcap \begin{array}{l|l}
A^{\prime} & \begin{array}{l}
A^{\prime} \subseteq A \& A^{\prime} \text { is a maximal subset of } A \text { such that } \\
\left\{\neg p \mid p \in A^{\prime}\right\} \cup\{\phi\} \text { is consistent }
\end{array}
\end{array}\right\}
\end{aligned}
$$

In words, EXH strengthens $\phi$ (often called the 'prejacent') by negating alternatives $\psi$ that are innocently excludable. Innocently excludable alternatives are defined as in (22-b), which are, informally speaking, those alternatives that can be negated together without creating a contradiction with the prejacent or entailing the truth of other alternatives. Most often, the innocently excludable alternatives will be all the alternatives that the prejacent does not entail (non-weaker alternatives), and in this section, we confine our attention to such cases (we will see later on a case with disjunction where this is not so). We often omit $\operatorname{Alt}(\phi)$ when its content is clear

Here is an illustration with a simple example.

Some of the students smoke.

To simplify the discussion, let us assume that All of the students smoke is the only alternative to (23). Then, given that the negation of this alternative is consistent with $\phi$, the following meaning is predicted.

$\llbracket$ EXH some of the students smoke $\rrbracket(w)=1$ iff both of the following hold:

a. $\llbracket$ some of the students smoke $\rrbracket(w)=1$

(Literal Meaning)

\footnotetext{
15 We leave unanswered here the question of how to implement the ideas presented in this section and below in other theories of presupposition.
} 
b. $\llbracket$ all of the students smoke $\rrbracket(w)=0$

(Scalar Implicature)

This way, we obtain the scalar implicature that not all of the students smoke.

In the previous studies on scalar implicature, it is largely left open what will happen when the alternatives $\psi$ have presuppositions. Fox's (2007) definition in (22) above makes no particular commitment about how presuppositions of alternatives should work. Let us discuss how we could fix this.

Within a trivalent framework, the definition in (22) above cannot be used innocuously, because we need first to define the notion of consistency in a trivalent setting (several definitions are in principle possible, cf. fn.17) and to determine what it means to negate a potentially undefined alternative. Let us focus here on the second issue, namely how to negate alternatives (we will return to the first issue later). In a bivalent setting, saying that an alternative is not true is the same as saying that it is false, so that the part of (22-a) that reads ' $\llbracket \psi \rrbracket(w) \neq 1$ ' is equivalent to ' $\llbracket \psi \rrbracket(w)=0$ '. This equivalence breaks down in a trivalent setting. That is, negating an alternative could be defined either as asserting that it is false (in which case the negation of an undefined alternative is itself undefined), or as asserting that it is not true, i.e. is false or undefined (in which case the negation of an undefined alternative is true). We call these two notions of negation strong negation $(-)$ and weak negation $(\sim)$, respectively:

$$
\begin{aligned}
& \llbracket-\phi \rrbracket(w)= \begin{cases}1 & \text { iff } \llbracket \phi \rrbracket(w)=0 \\
\# & \text { iff } \llbracket \phi \rrbracket(w)=\# \\
0 & \text { iff } \llbracket \phi \rrbracket(w)=1\end{cases} \\
& \llbracket \sim \phi \rrbracket(w)= \begin{cases}1 & \text { iff } \llbracket \phi \rrbracket(w)=0 \text { or } \llbracket \phi \rrbracket(w)=\# \\
0 & \text { otherwise }\end{cases}
\end{aligned}
$$

In (22-a) the innocently excludable alternatives are stated to be not true. If we maintain (22-a) as written in a trivalent setting, when ExH adds the negation of a presuppositional alternative, this negation will be satisfied, in particular, if the alternative denotes \#. That is, the negation used here is weak negation. Concretely, consider (27), and assume, for the sake of the discussion, that its alternative John knows that all the students came is innocently excludable. (27) will then be true just in case (27-a) holds, which is itself equivalent to (27-b).

EXH(John knows that some of students came)

a. John knows that some of students came and the alternative John knows that all students came is false or underfined.

b. John knows that some of students came and either all the students came but John doesn't know it, or not all of the students came.

If instead we replace ' $\neq 1$ ' with ' $=0$ ' in (22-a), i.e. if we use strong negation, then the outcome is that when ExH adds the negation of a presuppositional alternative, the resulting proposition can be true only if this alternative is false, which entails that the presupposition of the alternative is met. In other words, we would now predict that the presupposition of the negated alternative projects. So now (27), repeated as (28) below, would presuppose that all students came and assert that John knows that some 
did but does not know that all did. For it to be true, in particular, (28-b) below should hold.

EXH(John knows that some of students came)

a. John knows that some of students came and the alternative John knows that all students came is false.

b. John knows that some of students came and all the students came but John doesn't know it.

In what follows, we will investigate both of these possible approaches. In Sect. 4 we will examine the first approach illustrated in (27), which uses weak negation. We will see that it improves on Gajewski and Sharvit's predictions, but also that it has a number of shortcomings. This will lead us to argue for a proposal that combines an approach based on strong negation, illustrated in (28), with an independent principle, which we will dub Presupposed Ignorance.

\section{A trivalent approach to exhaustivity based on weak negation and strict entailment}

In this section, we assume a trivalent approach to presuppositions and adopt a lexical entry for $\mathrm{EXH}$ (noted $\mathrm{EXH}^{1}$ ) where innocently excludable alternatives are negated in a weak sense, i.e. where the negation of an alternative is true as soon as the alternative is itself not true, or equivalently, is false or undefined. Putting aside for a moment the definition of innocent exclusion in a trivalent framework, and treating innocent exclusion as a place-holder (noted $I E^{l}$ ) for something to be defined later, we can state the general shape of the idea as follows.

$$
\begin{aligned}
& \llbracket \operatorname{ExH}_{A l t(\phi)}^{1} \phi \rrbracket(w) \\
& = \begin{cases}\# & \text { iff } \llbracket \phi \rrbracket(w)=\# \\
1 & \text { iff } \llbracket \phi \rrbracket(w)=1 \text { and for all } \psi \in I E^{1}(\phi, A l t(\phi)), \llbracket \psi \rrbracket(w)=0 \text { or \# } \\
0 & \text { iff } \llbracket \phi \rrbracket(w)=0 \text { or for some } \psi \in I E^{l}(\phi, A l t(\phi)), \llbracket \psi \rrbracket(w)=1\end{cases}
\end{aligned}
$$

Recall that weak negation $\sim$ is defined as follows:

$$
\llbracket \sim \phi \rrbracket(w)= \begin{cases}1 & \text { iff } \llbracket \phi \rrbracket(w)=0 \text { or } \llbracket \phi \rrbracket(w)=\# \\ 0 & \text { otherwise }\end{cases}
$$

Thus, (29) can be rephrased as follows:

$$
\mathrm{EXH}_{A l t(\phi)}^{1} \phi
$$

a. asserts $\phi$ and $\sim \psi$ of all alternatives $\psi \in I^{1}(\phi, A l t(\phi))$; and

b. presupposes whatever $\phi$ presupposes.

We now need to decide how to define innocent exclusion. The definition of innocent exclusion in (22-b) uses two notions that can be cashed out in different ways in a 
trivalent setting, namely consistency, and, again, negation. The logic behind this definition, however, should guide us in determining how we should define these notions once we have adopted the view that negated alternatives are negated in the sense of weak negation. Intuitively, in the most simple cases, an alternative should be viewed as excludable if its weak negation does not create a contradiction. ${ }^{16}$ So we will use weak negation as well in the definition of innocent exclusion. In addition, we will say that a set of trivalent propositions is consistent if there is a world in which they are all true. ${ }^{17}$

A set of propositions is consistent if there is a world in which they are all true.

Then, $I E^{1}$ can be defined as follows:

$$
\left.I E^{l}(\phi, A):=\bigcap \begin{array}{l|l}
A^{\prime} & \begin{array}{l}
A^{\prime} \subseteq A \& A^{\prime} \text { is a maximal subset of } A \text { such that } \\
\left\{\sim p \mid p \in A^{\prime}\right\} \cup\{\phi\} \text { is consistent }
\end{array}
\end{array}\right\}
$$

Let us see how things work in a very simple case where a sentence $S$ has just one alternative $S^{+}$. For $S^{+}$to be innocently excludable, it should be the case that $\left\{S, \sim S^{+}\right\}$ is consistent, i.e. that there is a world where both $S$ and $\sim S^{+}$are true. This is to say that there is a world in which $S$ is true and $S^{+}$is either false or undefined. This, in turn, is the case exactly if it is not the case that whenever $S$ is true, $S^{+}$is true as well. It is instructive to restate this in terms of the following notion of entailment.

$$
\phi \text { strictly entails } \psi \text { iff in every world where } \phi \text { is true, } \psi \text { is true as well. }
$$

Then, $\left\{S, \sim S^{+}\right\}$is consistent just in case $S$ does not strictly entail $S^{+}$. In such cases, $S^{+}$is innocently excludable.

Note that in a trivalent setting strict entailment so defined is merely one possible notion of entailment among many others. Another possible notion is Strawsonentailment, defined as follows (von Fintel 1999). ${ }^{18}$

$$
\phi \text { Strawson-entails } \psi \text { iff in every world where } \phi \text { is true, } \psi \text { is not false. }
$$

Importantly, it is possible for $S$ to Strawson-entail $S^{+}$, without also strictly entailing it.

Let us consider a case with only one maximal set of alternatives $A^{\prime}$ such that $\left\{\sim p \mid p \in A^{\prime}\right\}$ is consistent with the prejacent. Then, the effect of $\mathrm{EXH}^{1}$ is that it negates all alternatives in $A^{\prime}$ that are not strictly entailed by the prejacent, which can

\footnotetext{
16 Note that the notion of contradiction can receive different reasonable definitions in a trivalent setting, since contradiction can be defined in terms of consistency. See the next footnote.

17 There are alternative notions of consistency that one could employ here. For instance a set of propositions could be said to be consistent* if there is a world in which none of them is false. A yet more complex definition would be that a set of propositions is consistent if there is a world in which either all of them are true, or all but one are true and the remaining one is undefined, etc. By using different notions of consistency, keeping negation constant, we might include more or fewer alternatives in the set of innocently excludable alternatives. We do not investigate the consequences of all these possible choices here, and stick to the notion in (31) throughout the paper.

18 Incidentally, von Fintel (1999) defines the same notion as follows: S Strawson-entails $S^{\prime}$ just in case in every worlds where the presuppositions of $S^{\prime}$ are met and $S$ is true, $S^{\prime}$ is also true. This is equivalent to (34).
} 
include alternatives that are Strawson-entailed by the prejacent. That is, in such cases, we have:

$$
\llbracket \operatorname{ExH}_{A l t(\phi)}^{1} \phi \rrbracket(w)=\left\{\begin{aligned}
& \# \text { iff } \llbracket \phi \rrbracket(w)=\# \\
& 1 \text { iff } \llbracket \phi \rrbracket(w)=1 \text { and for all } \psi \in A l t(\phi) \text { such that } \\
& \phi \text { does not strictly entail } \psi, \llbracket \psi \rrbracket(w)=0 \text { or \# } \\
& 0 \quad \begin{array}{r}
\text { iff } \llbracket \phi \rrbracket(w)=0 \text { or for some } \psi \in A l t(\phi) \text { such that } \\
\phi \text { does not strictly entail } \psi, \llbracket \psi \rrbracket(w)=1
\end{array}
\end{aligned}\right.
$$

Concretely, this is what happens in the case of a sentence such as (2) (John is unaware that some of the students smoke):

(36) $\operatorname{ExH}^{1}(\mathrm{John}$ is unaware that some of the students smoke)

This is predicted to be true just in case both of the following are the case:

- The presupposition and assertion of the prejacent is true:

$\exists x \in \operatorname{student}[\operatorname{smoke}(x)] \wedge \neg B_{j}(\exists x \in \operatorname{student}[\operatorname{smoke}(x)])$

- The 'all'-alternative is either false or yields presupposition failure:

$\left.\left[\forall x \in \operatorname{student}[\operatorname{smoke}(x)] \wedge B_{j}(\forall x \in \operatorname{student}[\operatorname{smoke}(x)])\right]\right]$

$\vee[\neg \forall x \in \operatorname{student}[\operatorname{smoke}(x)]]$

(presupposition failure)

Notice that the alternative John is unaware that all of the students smoke cannot be false when the prejacent is true, because its assertive meaning is entailed by the assertive meaning of the prejacent. That is to say, the prejacent Strawson-entails the alternative. Therefore, the overall inference is that the presupposition of the alternative is not met, i.e. not all of the students smoke, which is exactly what Gajewski and Sharvit observe.

What if the prejacent does not Strawson-entail the alternative? In such a case, a weaker inference is predicted. For instance, consider (1) (John is aware that some of the students smoke), analyzed as (37).

(37) $\operatorname{EXH}^{1}$ (John is aware that some of the students smoke)

This is predicted to be true just in case both of the following are true:

- The presupposition and assertion of the prejacent is true, i.e.

$\exists x \in \operatorname{student}[\operatorname{smoke}(x)] \wedge B_{j}(\exists x \in \operatorname{student}[\operatorname{smoke}(x)])$

- The 'all'-alternative is either false or presupposition failure:

$\left.\left[\forall x \in \operatorname{student}[\operatorname{smoke}(x)] \wedge \neg B_{j}(\forall x \in \operatorname{student}[\operatorname{smoke}(x)])\right]\right]$

$\vee[\neg \forall x \in \operatorname{student}[\operatorname{smoke}(x)]]$

(presupposition failure)

This time, the prejacent is compatible with both of the disjuncts of the scalar implicature, as it does not Strawson-entail the prejacent. As a consequence, the predicted scalar implicature is disjunctive: either [all of the students smoke but John doesn't know that] or [not all of the students smoke].

This allows us to account for the positive vs. negative asymmetry which was a problem for Gajewski and Sharvit's proposal, as discussed in Sect. 2.2. That is, for the negative sentence (36), we obtain the scalar implicature that not all of the students came, but for the positive sentence (37), the predicted scalar implicature is disjunctive 
and weaker. Moreover, this disjunctive inference seems to correspond to the intuitively available reading. First, consider the situation in (15) where we know that all of the students smoke, repeated here with stress annotation:

CONTEXT: We know that all of the students smoke.

A: John has absolutely no idea about what kind of students we have in this department. He probably doesn't know how rampant smoking is among the professors and students.

B: Yes, but he is aware that SOME of the students smoke.

In this context, the presupposition of the 'all'-alternative is satisfied, so the predicted scalar inference is that the 'all'-alternative is false, i.e. John doesn't know that all of the students came. This is exactly what the sentence means in this context.

Second, in a context where it is not presupposed that not all of the students came, we obtain a disjunctive reading. Consider the following context, for instance.

(39) ConteXt: We know that at least some of the students smoke, and are wondering whether all do.

A: Doesn't John know about the students' smoking habits?

B: Well, he is aware that SOME of the students smoke.

An intuitive paraphrase of the meaning of the sentence in the given context is disjunctive, i.e. either all of the students came but John doesn't know that, or not all of the students came, which is exactly what the present theory predicts.

Now, the second problem for Gajewski and Sharvit's analysis had to do with a sentence such as (19) repeated below as (40) from Sect. 2.3.

John forgot to do a few push-ups.

Recall that Gajewski and Sharvit's analysis predicts (40) to presuppose that John was supposed to do a few push-ups and not to do many push-ups. We now correctly predict a strictly weaker implicature, namely that John did not have to do many push-ups (which does not exclude that he could do many push-ups if he wanted to). This is so because (40), which uses a verb whose assertive part is negative ('John did not do push ups') but whose presupposition is positive ('John had to do a few push-ups') is Straswon-entailed, but not strictly entailed, by its alternative ('John forgot to do many push-ups'), and this alternative is therefore innocently excludable. Applying ExH ${ }^{1}$ thus amounts to asserting that the alternative is not true. As in the case of (2), the only way the alternative can be non-true if the prejacent is true is by being undefined. Given the alternative presupposes John had to do many push-ups, then, the resulting strengthened meaning is the prejacent conjoined with the proposition that John did not have to do many push-ups.

Thus, $\mathrm{EXH}^{1}$ is able to solve the two problems we noted for Gajewski and Sharvit's proposal. Furthermore, we would like to stress that $\mathrm{EXH}^{1}$ is a very natural extension of the bivalent definition of EXH given in (22) in the following sense. Essentially, what EXH says is that none of the innocently exludable alternatives $\psi$ can be true. When $\psi$ has presuppositions, there are two different ways for $\psi$ to be non-true, i.e. 
$\psi$ is false or $\psi$ yields a presupposition failure. ${ }^{19}$ When the 'assertive part' of an alternative is entailed by the prejacent (i.e. when the alternative is Strawson-entailed by the prejacent), the only way this alternative could be non-true when the prejacent is true is if it is undefined, i.e. if its presupposition is false.

One concern of this theory should be mentioned at this moment, however. As the astute reader might have noticed, it derives the relevant scalar inferences of (1) and (2) as part of the assertive meaning, rather than as part of the presupposition, unlike in Gajewski and Sharvit's account. In fact, a hey-wait-a-minute test (von Fintel 2004; von Fintel and Matthewson 2008) suggests the scalar inference of (2) is presuppositional in nature.

(41) A: John is unaware that some of the students smoke.

B: Hey wait a minute! I didn't know that not all of the students smoke!

The baseline here is that an ordinary scalar implicature in assertive meaning yields an anomaly in this test, as shown in (42).

A: Some of the students smoke.

B:\#Hey wait a minute! I didn't know that not all of the students smoke!

However, given the controversy regarding the interpretation of the hey-wait-a-minute test itself (Potts 2008; Tonhauser et al. 2011), this observation, although important, might not be decisive to negatively appraise the present theory. In what follows, we will present two additional observations which indicate that something important is amiss under this account.

\subsection{Effects of stress and the notion of vacuity}

As remarked at the end of Sect. 2, stress has interpretive effects. Especially important is the following contrast, which, to the best of our knowledge, has not been noticed before. Specifically, the prosody in (43-a) is natural and yields a very clear scalar implicature to the effect that John is not aware that all of the students smoke, while (43-b) does not sound as natural.

a. John is aware that SOME of the students smoke.

b.\#?John is unaware that SOME of the students smoke.

\footnotetext{
19 In other words, if $\psi_{p}$ is an innocently excludable alternative whose presupposition is $p$, EXH ${ }^{1}$ adds to the prejacent the classical negation of $p \wedge \psi_{p}$. The idea that, for the purpose of implicature computation, the presuppositional content of alternatives should be treated as being part of their 'assertive' truth-conditions has been around for quite some time in informal discussions, in connection with Sharvit and Gajewski's (2008) observation (Luka Crnič p.c., Danny Fox p.c., among others), but as far as we know has not appeared in a published form, with the exception of a brief discussion in Spector (2014). It would also be very natural in a non-trivalent approach to presupposition, such as Schlenker (2008) or Chemla (2009), in which presuppositions are just part of the truth-conditions of sentences. A version of Chemla (2009) (technically, one where 'multiple replacements' are not used in the relevant cases) exactly corresponds to this. This version would generate the inference numbered (130b) in Chemla $(2009,50)$, without generating (130b-i) and (130b-ii).
} 
This pair demonstrates that the scalar item some tends to resist stress when it occurs under unaware but not when it occurs under aware. ${ }^{20}$ Observe, furthermore, that the judgment reverses with all, with (44-b) implying that John is aware that some of the students smoke. ${ }^{21}$

a.\#?John is aware that ALL of the students smoke.

b. John is unaware that ALL of the students smoke.

Moreover, the exact same contrasts obtain with overt only, perhaps more sharply.

a. John is only aware that SOME of the students smoke.

b. \#John is only unaware that SOME of the students smoke.

a. \#John is only aware that ALL of the students smoke.

b. John is only unaware that ALL of the students smoke.

Why are the above infelicitous sentences infelicitous? Their infelicity seems to be of the same nature as other infelicitous examples involving vacuous exhaustification., which is a general restriction on exhaustification. It is a well-known generalization that scalar implicatures are computed from low scalar items like some in increasing contexts (e.g. under John thinks) but not in decreasing contexts (e.g. under John doubts) as demonstrated by (47). ${ }^{22}$

a. John thinks that SOME of the students smoke.

(Scalar implicature: John doesn't think that all of the students smoke.)

b.\#?John doubts that SOME of the students smoke.

The same goes with only:

a. John only thinks that SOME of the students smoke. ( $\rightsquigarrow$ John doesn't think that all of the students smoke.)

20 A caveat is in order. The local implicature readings paraphrased by (i) are presumably also available, and hence strictly speaking, (43-b) is not infelicitous:

(i) a. John is aware that some but not all of the students smoke.

b. John is unaware that some but not all of the students smoke.

Assuming that these alternative readings are possible, if not very prominent, it is possible that they are responsible for the relative weakness of the contrast in comparison to the examples with overt only in (45) below. Since these readings are truth-conditionally distinguishable from the readings we are after, and are arguably quite marked, we will ignore them in the following discussion.

21 Unsurprisingly (44-a) has a felicitous reading with a metalinguistic construal of the focus, which generally requires a prior utterance to the contrary, as in (i).

(i) CONTEXT: We know that all of the students smoke.

A: John is only aware that SOME of the students smoke.

B: No, John is aware that ALL of the students smoke.

We will ignore metalinguistic readings here.

22 Both examples might allow readings with embedded implicatures (i.e. 'John thinks/doubts that some but not all of the students came'), which are again orthogonal to our main point here. 
b. \#John only doubts that SOME of the students smoke.

By contrast, scalar implicatures with high scalar items like all are observed in decreasing contexts (so-called 'indirect implicatures') but not in increasing contexts. ${ }^{23}$

a. John (\#only) thinks that ALL of the students came.

b. John doubts that ALL of the students came.

(Scalar implicature: It is not impossible that some of the students came.)

These observations can be understood as follows: scalar implicatures arise in contexts where there are alternatives that can be negated without giving rise to a contradiction, or equivalently, exhaustification with EXH or only is non-vacuous, and in contexts where exhaustification is vacuous, infelicty ensues.

The behavior of stressed some and all under aware and unaware we pointed out above are very similar to this, and it is likely that the same principle is behind it. That is, the infelicitous examples like (43-b) should be infelicitous because they involve vacuous exhaustification.

However, notice that unaware is not simply decreasing due to the factive presupposition. More concretely, there are situations where John is unaware that Mary is a linguist is true but John is unaware that Mary is a semanticist fails to be true, namely contexts where the latter yields presupposition failure. In fact, unaware is actually a non-monotonic operator, as its meaning is the conjunction of a decreasing assertion and an increasing presupposition. Consequently, the anomaly of (43-b) cannot be characterized in terms of vacuity in terms of strict entailment.

Rather, we claim that vacuity here should be understood in terms of Strawsonentailment. To be formally precise, we genereralize the notion of Strawson-entailment as follows.

\section{Generalized Strawson-entailment}

If $f$ and $g$ are two $n$-place functions of type $\left\langle\sigma_{1} \ldots\left\langle\sigma_{n}, t\right\rangle\right\rangle$, then $f$ Strawsonentails $g$ iff for all entities $x_{1}$ of type $\sigma_{1}, \ldots, x_{n}$ of type $\sigma_{1}, \ldots, \sigma_{n}$, if $f\left(x_{1}\right) \ldots\left(x_{n}\right)=1$, then $g\left(x_{1}\right) \ldots\left(x_{n}\right) \neq 1$.

Then, Strawson-increasing and Strawson-decreasing environments are defined as follows.

(51) Let $S$ be a sentence and let $E$ be an occurrence in $S$ of an expression whose semantic type ends in $t$. For any function $x$ of the type of $E$, let us note $\llbracket \mathrm{S} \rrbracket^{x / E}$ the meaning that $S$ would receive if $E$ where interpreted as denoting $x$. Then,

23 There are felicitous uses of (49-a) without only, unlike (47-b), as in the following context:

(i) A: It's so strange that John asked us what kind of cigarettes we smoke. Maybe he doesn't know that not many people smoke here.

B: Yeah, he thinks ALL of the students smoke. Maybe when he was a student, almost everybody smoke.

One way to think about this is that all here contrasts with some with a local scalar implicature. That is, the first sentence of (i-B) emphasizes the fact that John doesn't think that some but not all of the students smoke. Although interesting, this reading is orthogonal to the point we are making here. 
$S$ defines a Strawson-increasing (resp. Strawon-decreasing) environment for $E$ just in case for any two functions of the appropriate type $x$ and $y$ such that $x$ Strawson-entails $y, \llbracket \mathrm{S} \rrbracket^{x / E}$ Strawson-entails $\llbracket \mathrm{S} \rrbracket^{y / E}$ (resp. $\llbracket \mathrm{S} \rrbracket^{y / E}$ Strawsonentails $\llbracket \mathrm{S} \rrbracket^{x / E}$ ).

Notice that all increasing functions are Strawson-increasing, but the converse does not hold; similarly, all decreasing functions are Strawson-decreasing, but not vice versa (Gajewski 2011).

Using these notions, our observation can be summarized as follows: with or without an overt only, stress on a low scalar item such as some sounds natural when it occurs in a Strawson-increasing context (e.g. under aware) but not when it occurs in a Strawsondecreasing context (e.g. under unaware). Stress on a high scalar item such as all, on the other hand, sounds more natural in a Strawson-decreasing context than in a Strawson-increasing context.

This state of affairs is not explained in the account we have been discussing. Recall, in particular, that $\mathrm{EXH}^{1}$ (implicitly) relies on a notion of logical strength based on strict entailment rather than Strawson-entailment. Consequently, it is not vacuous in sentences such as (43-b) with Strawson-decreasing operators like unaware. Rather, it is predicted to derive the scalar inference that not all of the students smoke (just as in the case of the version of the sentence without a stress on some). More generally, this account misses the semantic effect of stress, and falls short of accounting for the natural generalization of the distribution of stressed scalar items in terms of vacuity of exhaustification. Similarly, Gajewski and Sharvit's account has the same problem, and cannot predict the contrast in (43). In Sect. 5, we will define another exhaustivity operator based on Strawson-entailment rather than strict entailment, which corresponds to the second option discussed in Sect. 3.

\subsection{Presupposed ignorance}

Another phenomenon that remains unaccounted for under the present analysis, as well as under Gajewski and Shavit's, has to do with what we call presupposed ignorance. Let us consider the example in (4), repeated here, which contains a presupposition trigger too together with an 'ignorance-inducing' scalar item or.

(4) Mary will go to Yale. \#John, too, will go to Yale or Harvard.

If the first sentence also contains the same disjunction, the sentence becomes felicitous (modulo the slight infelicity of repeating the proper names).

Mary will go to Yale or Harvard. John, too, will go to Yale or Harvard.

According to standard treatments of the focus-sensitive particle too, the infelicity of (4) is puzzling. Specifically, the second sentence of (4) should have a so-called anaphoric presupposition. That is, for it to be felicitous, there should be a salient individual $d$ distinct from John (called the antecedent) such that it is common knowledge that $d$ will go to Yale or $d$ will go to Harvard. In (4), Mary should be able to serve as the antecedent, because by the time the second sentence is uttered, it is common knowledge 
that Mary will go to Yale, which entails that it is common knowledge Mary will go to Yale or Harvard (see fn.24 for a caveat).

A similar example can be constructed with other presupposition triggers, including Strawson-decreasing factive predicates like unaware (we will discuss to Strawsonincreasing cases in the next section).

(53) CONTEXT: It's common knowledge between speaker and addressee that Mary speaks English but not French.

\#John is unaware that Mary speaks English or French.

Again, it is not immediately clear why this example should be infelicitous. The factive presupposition should be that Mary speaks English or Mary speaks French, which is satisfied in the context given here, as it is commonly known that Mary speaks English, which entails that it is commonly known that Mary speaks English or French.

Furthermore, analogous examples can be constructed with other ignoranceinducing scalar items, such as at least and at most.

a. Mary has three kids. \#John, too, has at least two kids.

b. Mary has just turned 35 years old. \#John, too, is at most 35 years old.

a. CONTEXT: It is common knowledge that John has three kids.

\#Mary is unaware that John has at least two kids.

b. CONTEXT: It is common knowledge that John turned 35 yesterday.

\#Mary is unaware that John is at most 35 years old.

The infelicity of the examples above simply does not lend itself to the analysis of the interactions between scalar inferences and presuppositions that we considered in the present section or to Gajewski and Sharvit's. Thus under these accounts, it requires a separate theoretical treatment. It seems to us that presupposed ignorance should be considered part of the empirical landscape of interactions between scalar implicatures and presuppositions. In fact we will claim below that whatever accounts for presupposed ignorance actually accounts for Gajewski and Sharvit's observation as well.

\section{Presupposed ignorance principle and EXH}

In the present section, we offer a novel view on the interactions between scalar inferences and presuppositions. We will start with a way to account for presupposed ignorance, and demonstrate that the same mechanism accounts for Gajewski and Sharvit's observation regarding scalar inferences triggered in Strawson-decreasing environments such as (2). We will also see, however, that it fails to account for scalar inferences triggered in Strawson-increasing environments such as (1), for which we suggest a different scalar strengthening mechanism, which relies on a different definition of ExH from the one we considered in the previous section. We will show that the resulting theory not only captures presupposed ignorance, but also the notion of vacuity that is key to the understanding of the interaction between prosody and monotonicity we saw above. 


\subsection{Presupposed ignorance principle}

In order to account for the presupposed ignorance data, we propose the principle in (56). In what follows, we write $C K_{c}(p)$ to mean 'the common knowledge in $c$ entails $p^{\prime}$ (the subscript $c$ is omitted when no ambiguity arises), and say that $p$ is the presupposition of $\phi$ if a) $\phi$ presupposes $p$ and b) every proposition presupposed by $\phi$ is entailed by $p$.

Presupposed Ignorance Principle (PIP):

Let $p$ be the presupposition of sentence $\phi$. If $\phi$ has an alternative $\psi$ whose presupposition is $q$ and $q$ asymmetrically entails $p, \phi$ is infelicitous in context $c$ if $q$ is satisfied in $c$, i.e. $C K_{c}(q)$.

This principle introduces a 'presupposed ignorance inference' that $\neg C K(q)$ based on alternatives $\psi_{q}$ to the uttered sentence $\phi_{p}$ whose presupposition $q$ is stronger than $p$. By way of illustration, let us apply it to (4). We assume Sauerland's (2004) scale for disjunction, i.e. the alternatives to $\phi$ or $\psi$ are $\phi, \psi$ and $\phi$ and $\psi$. Thus, the following three are the relevant alternatives:
a. John, too, will go to Yale.
b. John, too, will go to Harvard.
c. John, too, will go to Yale and Harvard.

Keeping Mary as the antecedent, these sentences have the following presuppositions, respectively.
a. Mary will go to Yale.
b. Mary will go to Harvard.
c. Mary will go to Yale and Harvard.

Notice that all of these asymmetrically entail the presupposition of the second sentence John, too, will go to Yale or Harvard (provided that Mary is the antecedent). Thus, (56) derives the following inferences.
a. $\neg C K$ (Mary will go to Yale)
b. $\neg C K$ (Mary will go to Harvard)
c. $\neg C K$ (Mary will go to Yale and Harvard)

Now (59-a) is in conflict with the first sentence of (4), which explains the anomaly. If, on the other hand, the first sentence is compatible with all of these inferences, the sentence becomes good, as illustrated by (52), repeated here. ${ }^{24}$

\footnotetext{
24 The audience of LFRG at MIT (June 2, 2014) pointed out that the following example has a felicitous reading, unlike (4).
}

(i) Mary will go to Oxford. (?)John, too, will go to Oxford or Cambridge.

As David Pesetsky (p.c. to Y.S.) suggested, if this is uttered in a context where the primary interest of the conversation is to find out who went to Oxford or Cambridge, the sentence sounds better. We claim that this observation is not incompatible with our analysis on the assumption that in such a context, the set of alternatives is 
(52) Mary will go to Yale or Harvard. John, too, will go to Yale or Harvard.

The PIP (56) offers analogous explanations to the other examples of presupposed ignorance raised in the previous section. To save space, we will only demonstrate it for (54-a), repeated here.

(54-a) Mary has three kids. \#John, too, has at least two kids.

The idea is to treat at least two as having alternatives of the form at least $n$ and exactly $n$ (see Büring 2007 and, for a recent detailed investigation of this approach, Schwarz 2016). Crucially, then, the alternatives to the second sentence above include John, too, has at least three kids, which presupposes, with Mary being the antecedent, that Mary has at least three kids. This is stronger than the presupposition of the second sentence of (54-a), so the PIP derives the inference $\neg C K$ (Mary has at least three kids), which contradicts the assertion of the first sentence.

Before moving on, it should be remarked that the principle as stated in (56) is admittedly rudimentary, and a deeper explanation should be sought, possibly by reducing it to more general pragmatic principles. However, this seems to be a rather strenuous task at this moment and likely to require a whole lot of further research, and we need to leave this task for another occasion (but see Sect. 6 some discussion). Fortunately, for the purposes of the present paper, it is sufficient to assume some mechanism that derives presupposed ignorance inferences, without knowing exactly where that mechanism comes from. Specifically, all we would like to demonstrate here is that part of the interactions between scalar implicatures and presuppositions, in particular Gajewski and Sharvit's observation, can be accounted for as a species of presupposed ignorance inferences, and for this purpose, (56) is enough.

Also, one might notice that the PIP (56) resembles Maximize Presupposition (MP) postulated by Heim (1991), among others. However, it is important to realize that these two principles are distinct (at least under the standard construal of MP). Simply put, MP renders a sentence $S$ infelicitous when $S$ is contextually equivalent to some alternative $S^{\prime}$ whose presuppositions entail those of $S$. However, for cases we have been discussing, the context does not make the sentence and its alternatives contextually equivalent, which is easily seen with examples like (4), where the alternatives have stronger assertions, as well as a stronger presuppositions. Thus, MP does not yield presupposed ignorance inferences. This point is discussed in more detail in the Appendix.

\subsection{Back to Gajewski and Sharvit's observation}

Let us now return to Gajewski and Sharvit's observation that the Strawson-decreasing example (2) presupposes that not all of the students smoke (when no stress is placed on some), i.e. (6).

Footnote 24 continued

contextually restricted to exclude the ones based on the disjuncts (cf. Fox and Katzir 2011 for relevant discussion). 
(2) John is unaware that some of the students smoke.

(6) a. ASSERTION: $\neg B_{j}(\exists x \in \operatorname{student}[\operatorname{smoke}(x)])$

b. PRESUPPOSITION: $[\exists x \in \operatorname{student}[\operatorname{smoke}(x)]] \wedge[\neg \forall x \in$ student $[\operatorname{smoke}(x)]]$

We noted that in accordance with their analysis, in a context where it is commonly known that all of the students smoke, (2) is judged as infelicitous, as shown in (7).

(7) CONTEXT: John wonders if any students smoke. We know all do.

\#John is unaware that some of the students smoke.

We claim that the infelicity of (7) can be accounted for by the PIP (56). The relevant alternative here is the 'all'-alternative, (60), which presupposes that all of the students smoke.

(60) John is unaware that all of the students smoke.

Based on (60), the PIP derives the presupposed ignorance inference that $\neg C K$ (all of the students smoke), which is violated in (7).

Notice that the predicted inference is weaker than what Gajewski and Sharvit proposed. That is, it is only required that it be not common knowledge that the presuppositions of the alternatives are satisfied, rather than it be common knowledge that the presuppositions of the alternatives are false. But we think that this is not a bad prediction, and in fact is even an empirical advantage. That is, as we noted in passing in fn.8, (2) seems not to be infelicitous in a context where it is not known that not all of the students smoke, as shown in in (61).

(61) CONTEXT: We know some of the students in the department are smokers but are not sure if all are.

A: I think John is the person to ask about the students.

B: I don't think so. In fact, he is unaware that some of the students smoke.

That said, we do believe that the stronger inference that Gajewski and Sharvit assigned can indeed arise, especially out of the blue. To capture this, we assume that inferences that $\neg C K_{c}(p)$ can be strengthened into $C K_{c}(\neg p)$ with an auxiliary pragmatic reasoning, as previously proposed by Chemla (2008) (see Sauerland 2004 for scalar implicatures). In order to keep the discussion simple, we abstain from presenting the details of this mechanism here, and simply refer the interested reader to Chemla (2008).

\subsection{A trivalent exhaustivity operator based on strong negation}

However, the PIP in (56) makes wrong predictions for Strawson-increasing examples like (1).

(1) John is aware that some of the students smoke. 
As we remarked in Sect. 2.2, this sentence, unlike its Strawson-decreasing counterpart (2), is felicitous in contexts where it is common knowledge that all of the students smoke, especially with a stress on some.

\section{CONTEXT: We know that all of the students smoke.}

A: John has absolutely no idea about what kind of students we have in this department. He probably doesn't know how rampant smoking is among the professors and students.

B: But he is aware that some of the students smoke.

However, the PIP derives the same presupposed ignorance inference as before, i.e. $\neg C K$ (all of the students smoke), which should be inconsistent with the context in (61) and render the sentence infelicitous, contrary to fact.

We claim that for cases like this, a different scalar strengthening mechanism is at play, namely EXH. The version of EXH we need, however, is different from EXH ${ }^{1}$ we considered in the previous section with respect to how it deals with the presuppositions of the alternatives. Recall that $\mathrm{EXH}^{1}$ is a straightforward interpretation of the original bivalent definition of EXH in some sense, but its projection property is basically stipulated. That is, we formulated $\mathrm{EXH}^{1}$ so that it behaves as a 'presupposition plug' for negated alternatives in the sense that the whole sentence with $\mathrm{EXH}^{1}$ does not inherit the presuppositions of the negated alternatives. Specifically, EXH was defined as negating alternatives in the weak sense, i.e. where negating an undefined sentences gives rise to falsity rather than undefinedness.

Instead, we postulate a version of EXH with a presupposition projection property that is conceptually more attractive. That is, given that EXH functions as a kind of negation (and conjunction) for the negated alternatives, it is more natural to expect that it passes up the presuppositions of the alternatives it negates, just like negation passes up the presupposition of the sentence it negates. In other words, EXH should behave as a 'presupposition hole' with respect to the negated alternatives. ${ }^{25}$ In order to achieve this, we make use of strong negation, instead of weak negation, in the definition of innocent exclusion, and then of ExH (but we keep the same notion of consistency). We call this version of the exhaustivity operators $\mathrm{EXH}^{2}$.

As mentioned, we now use strong negation (-) defined as follows:

$$
\llbracket-\phi \rrbracket(w)= \begin{cases}1 & \text { iff } \llbracket \phi \rrbracket(w)=0 \\ \# & \text { iff } \llbracket \phi \rrbracket(w)=\# \\ 0 & \text { iff } \llbracket \phi \rrbracket(w)=1\end{cases}
$$

\footnotetext{
${ }^{25}$ It is also a conceptual advantage of this analysis that the projective properties of EXH and only are identical, as explained in Sect. 5.4. In addition it is closer to the spirit of predictive theories of presupposition projection (cf. Fox 2008; George 2008; Schlenker 2008, 2009; Rothschild 2011), whose central tenet is that the way presuppositions project in the scope of an operator is fully determined by the truth-conditional contribution of the operator (as it can be assessed when it takes non-presuppositional arguments). See also Mayr and Romoli (2016) for a related discussion of how presuppositions are predicted to project under the scope of EXH in disjunctive and conditional sentences, within the framework of Schlenker $(2008,2009)$.
} 
Innocent exclusion is then defined as follows. The only change is that now strong negation is used. In particular, the notion of consistency is the same as before, namely (31).

$$
\left.I E^{2}(\phi, A):=\bigcap \begin{array}{l|l}
A^{\prime} & \begin{array}{l}
A^{\prime} \subseteq A \& A^{\prime} \text { is a maximal subset of } A \text { such that } \\
\left\{-p \mid p \in A^{\prime}\right\} \cup\{\phi\} \text { is consistent }
\end{array}
\end{array}\right\}
$$

Finally, $\mathrm{EXH}^{2}$ is defined as follows:

$$
\begin{aligned}
& \llbracket \operatorname{ExH}_{A l t(\phi)}^{2} \phi \rrbracket(w) \\
& =\left\{\begin{array}{cc}
\# \text { iff } \llbracket \phi \rrbracket(w)=\# \text { or for some } \psi \in I E^{2}(\phi, \operatorname{Alt}(\phi)), \llbracket \psi \rrbracket(w)=\# \\
1 & \text { iff } \llbracket \phi \rrbracket(w)=1 \text { and for all } \psi \in I E^{2}(\phi, \operatorname{Alt}(\phi)), \llbracket \psi \rrbracket(w)=0 \\
0 & \text { iff } \llbracket \phi \rrbracket(w)=0 \text { or for some } \psi \in I E^{2}(\phi, \operatorname{Alt}(\phi)), \llbracket \psi \rrbracket(w)=1 \\
\text { and for no } \psi \in I E^{2}(\phi, A l t(\phi)), \llbracket \psi \rrbracket(w)=\#
\end{array}\right.
\end{aligned}
$$

In words, (63) yields a presupposition failure if $\phi$ or an innocently excludable alternative $\psi$ to $\phi$ yields a presupposition failure. If this is not the case, it is true just in case $\phi$ is true and all the innocently excludable alternatives $\psi$ are false. Equivalently:

$$
\mathrm{EXH}_{A l t(\phi)}^{2} \phi
$$

a. asserts $\phi$ and the strong negation of all alternatives $\psi \in \operatorname{IE}^{2}(\phi, \operatorname{Alt}(\phi))$;

b. presupposes whatever $\phi$ presupposes and the negated alternatives $\psi$ presuppose.

With $\mathrm{EXH}^{2}$, we analyze (1) as (65) (the subscript on $\mathrm{EXH}^{2}$ is suppressed, as before).

$$
\text { EXH John is aware that SOME of the students smoke. }
$$

Assuming that the alternative to the prejacent of EXH is 'John is aware that all of the students smoke', we predict that (65) presupposes that all of the students smoke, and asserts that John does not know this but knows that some do. This scalar implicature is exactly what we intuitively perceive in contexts where it is presupposed that all of the students came, as we already saw in (15).

Notice importantly that the PIP (56) is vacuous for (65), because (65), which contains $\mathrm{EXH}^{2}$, already presupposes that all of the students smoke and its alternatives, which also contain $\mathrm{EXH}^{2}$, presuppose the same thing. Therefore, there is no alternative with a stronger presupposition, and no presupposed ignorance inference is derived, as desired. To obtain this result, it is crucial that the computation of scalar implicatures takes place before the PIP (56) applies. We simply stipulate here that it is the case, but this ordering is natural if $\mathrm{EXH}^{2}$ is a grammatical operator while the PIP is a pragmatic principle.

Now one might wonder why $\mathrm{EXH}^{2}$ is not used in the Strawson-decreasing example. This has to do with vacuous exhaustification mentioned in Sect. 4.1 above. It also has a close connection with the notion of Strawson-entailment. Before getting there, we will make a short digression on only, which will facilitate the discussion to follow. 


\subsection{Only}

It is often remarked that EXH and only are very similar in meaning (Fox and Hackl 2006; Fox 2007; Chierchia et al. 2012). We take this analogy with overt only seriously, and assume that only also behaves like a presupposition hole with respect to nonweaker alternatives. In fact, that only is a presupposition hole is empirically motivated on independent grounds. For instance, (66) presupposes that all the 10 boys used to smoke (and asserts that all but John are still smoking). ${ }^{26}$

Of the 10 boys, only JOHN quit smoking.

This universal presupposition is expected if the presuppositions of the alternatives of the prejacent must become presuppositions of the entire sentence.

To be more precise, we adopt the standard Roothian alternative semantics for focus (Rooth 1985, 1992), and assume that EXH and only associate with focus in the same manner (cf. Fox and Katzir 2011). In the case of (66), for example, the alternatives to the prejacent of only are sentences of the form ' $a$ stopped smoking' where $a$ is a contextually relevant referring expression. Notice that all of these alternatives, which can be negated, presuppose that $a$ used to smoke, and these presuppositions are inherited by the entire sentence, which amounts to a universal presupposition that all of the 10 boys used to smoke.

Now given this analysis of only, it is not at all surprising to observe that only can be added to the relevant sentence in (15) without changing the overall meaning much, as shown in (67): ${ }^{27}$

CONTEXT: We know that all of the students smoke.

A: John has absolutely no idea about what kind of students we have in this department. He probably doesn't know how rampant smoking is among the professors and students.

B: Indeed, he is only aware that SOME of the students smoke.

\footnotetext{
26 Unfortunately the facts are not as simple as one might expect. Certain presuppositions, especially those triggered by phi-features, seem to not project universally through only (Spathas 2010; Jacobson 2012; Sudo 2012; Sauerland 2013). For instance, the uniqueness presupposition of the singular definite in (i) does not.

Of the 10 boys, only JOHN showed me the picture he took.

That is, (i) does not presuppose that all of the 10 boys took exactly one picture; rather, it only presupposes that John took exactly one picture. This is, however, only a complication and does not undermine the point we are making here that only and $\mathrm{ExH}^{2}$ have the same projection properties. For the sake of simplicity, we will not discuss presupposition triggers that do not universally project through only and $\mathrm{EXH}^{2}$ in this paper.

27 There is a slight change in the nuance of B's utterance. Intuitively, only emphasize the negative aspect that John knows only so much, while EXH ${ }^{2}$ emphasizes the positive aspect of the information that John is not totally ignorant. This interpretive difference should be attributed to the difference in the lexical semantics of only and $\mathrm{EXH}^{2}$, but we are only interested in their projection properties in this paper and will not attempt to capture this difference in formal terms.
} 
That is, the crucial alternative to the prejacent of only in (67-B) is the 'all'-alternative which presupposes that all of the students smoke. ${ }^{28}$

Now, it is important that only associates with a phonologically stressed item. We assume that this is the same for $\mathrm{EXH}^{2}$. As we will now see, this accounts for the effects of stress discussed in Sect. 4.1.

\subsection{Effects of stress and vacuous exhaustification}

Recall that the Strawson-decreasing sentences become infelicitous, when the scalar item is stressed, as in (68-a) and also when there is an overt only, as in (68-b).

a. \#John is unaware that SOME of the students smoke.

b. \#John is only unaware that SOME of the students smoke.

We account for this observation as follows. Firstly, we assume that a stress on some in (68-a) strongly correlates with the presence of $\mathrm{EXH}^{2}$. We assume, furthermore, that only and EXH are subject to the same constraint that prohibits vacuous uses. That is, in order for them to be felicitously used, there must be at least one alternative that can be negated without giving rise to a contradiction or a presupposition failure. We now show that this condition is not met in the examples in (68).

Assuming that all is an alternative to some, the relevant alternative to the prejacent is 'John is unaware that all of the students smoke'. Suppose first that the presupposition of this alternative is satisfied, i.e. it is commonly known that all of the students smoke. In this context, the assertive meaning of the prejacent 'John is unaware that some of the students smoke' entails the assertive meaning of the alternative. Therefore, there is no alternative that can be negated without making the whole sentence contradictory - exhaustification is vacuous. Now consider a different situation where the presupposition of the alternative is not satisfied, i.e. it is not commonly known that all of the students smoke. Then, since $\mathrm{EXH}^{2}$ and only are presupposition holes, the presupposition of the entire sentence is not satisfied. Therefore the sentence should yield a presupposition failure in this case. Thus, either case, the sentence is predicted to be infelicitous.

28 We mentioned in fn.7 that the Strawson-decreasing example (2) becomes felicitous in contexts where it is known that all of the students smoke with even a stress on some, as in (i) (compare this to (7)).

CONTEXT: John wonders if any students smoke. We know all do.

John is even unaware that SOME of the students smoke.

Being a focus sensitive item, even, just like only, invokes focus alternatives. Unlike only, however, even does not negate these alternatives and instead introduces scalar inferences based on them that prejacent is relatively unlikely (see Crnič 2011 and references therein). Since even only adds scalar inferences which are essentially modalized, it should not behave as a presupposition hole (we assume that the additive inference is not an essential part of the meaning of even, at least when it associates with a scalar item; see Rullmann 2003; Crnič 2011 for discussion). According to this idea, therefore, the sentence in (i) presupposes that there are smokers among the students but does not presuppose that all of the students smoke. In fact, the sentence in (i) can be used in a context where it is common knowledge that most but not all of the students smoke. Furthermore, it is correctly predicted that unlike only and EXH, the use of even is not vacuous in sentences like (i). 
The relative infelicity of stressed high scalar items like all in Strawson upward entailing contexts can be explained similarly. Recall the following sentences are infelicitous.

a. \#John is aware that ALL of the students smoke.

b. \#John is only aware that ALL of the students smoke.

As before, it is assumed that the stress is strongly correlated with the presence of $\mathrm{EXH}^{2}$ in (69-a). The relevant alternative to the prejacent in these sentences is 'John is aware that some of the students smoke'. Since the assertion of this sentence is already entailed, it cannot be negated, hence the infelicity.

To reiterate the crucial points, stress is assumed to correlate with the use of $\mathrm{EXH}^{2}$ (or only). When a scalar item is stressed, one tends to parse the sentence with $\mathrm{EXH}^{2}$ and when a scalar item is not stressed, one tends to parse the sentence without $\mathrm{EXH}^{2}$. When used in Strawson-increasing contexts like (1), EXH ${ }^{2}$ strengthens the presuppositions, thereby bleeding the PIP. On the other hand, $\mathrm{EXH}^{2}$ is vacuous in Strawson-decreasing examples like (2), and consequently the PIP has non-trivial effects. These account for the following sentences.

a. John is (only) aware that SOME of the students smoke.

b. \#John is (only) unaware that SOME of the students smoke.

c. John is unaware that some of the students smoke.

For the sake of completeness, we need to discuss what happens when a non-stressed scalar items occurs in a Strawson-increasing context. As we expect, in such a case, the PIP will kick in and derive the negation of the presuppositions of the negated alternatives. In order to see this, consider the following example with a focal stress on John and with the material following it de-accented. ${ }^{29}$

\footnotetext{
29 We also leave it a possibility that $\mathrm{EXH}^{2}$ is used in the embedded clause with a stress on some, which would render the sentence synonymous with (i).
}

(i) John is aware that some but not all of the students smoke.

Also, we are making here an important assumption that some in sentences like (71) need not be associated with $\mathrm{EXH}^{2}$. We further assume that some needs to be stressed in order to trigger an scalar implicature. This, however, is a simplification. If $\mathrm{EXH}^{2}$ is focus-sensitive, we expect that what is needed for the alternative all to contribute to the relevant focus value is that some belongs to a focussed constituent (so that its alternatives contribute to the focus value of the sentence). But this can be the case even if some itself is not stressed, given standard assumptions about how prosody constrains focus marking. What is clear is that if some itself bears focal stress, its alternatives must contribute to the focus value, and this is sufficient to predict the contrasts under discussion (that is, it predicts that stress on some facilitates the computation of the scalar implicature triggered by the some/all competition, which is sufficient to predict contrasts regarding the perceived availability of various readings depending on stress patterns). We furthermore expect that when the sentence contains just one focussed constituent and this constituent does not contain some, no scalar implicature should arise. For instance, no scalar implicature is expected in the following example:

(ii) JOHN read some of the books.

Experimental results in Zondervan (2010) show that a sentence such as (ii) is less likely to trigger the inference that John didn't read all of the books than the very same sentence with a different prosody. However, rates of derivation of the associated scalar implicature for sentences such as (ii) were found to be 
(71) CONTEXT: We know that all of the students smoke.

A: The faculty in this department have absolutely no idea how rampant smoking is among the students today.

B:\#Well, but JOHN is aware that some of the students smoke.

We account for this with the PIP in the same manner we accounted for the Strawsondecreasing counterpart of this example. That is, the 'all'-alternative to this sentence has a stronger presupposition that all of the students smoke, from which the PIP derives the inference that $\neg C K$ (all of the students smoke). This presupposed ignorance inference is not satisfied in the given context.

\subsection{Disjunctive contexts and local accommodation}

Before leaving this section, let us discuss the disjunctive interpretation of sentences like (1). It was remarked in Sect. 4 that one obtains a disjunctive interpretation for examples like (39), repeated below.

(39) ConteXt: We know that at least some of the students smoke, and are wondering whether all do.

A: Doesn't John know about the students' smoking habits?

B: Well, he is aware that SOME of the students smoke.

Here the sentence seems to mean that either [all of the students smoke and John doesn't know that] or [not all of the students smoke]. This is not predicted if the presupposition of the alternative must be true. The same goes with an overt only:

(72) CONTEXT: We know that at least some of the students smoke, and are wondering whether all do.

A: Doesn't John know about the students' smoking habits?

B: Well, he is only aware that SOME of the students smoke.

We propose that what is going on in the above examples is 'local accommodation' of the presupposition under EXH/only. In order to formally capture local accommodation, we make use of the $\mathcal{A}$-operator, defined as follows (Bochvar 1981; Beaver and Krahmer 2001).

$$
\begin{aligned}
& \text { Accommodation operator }(\mathcal{A}) \\
& \mathcal{A}(\llbracket \phi \rrbracket)(w)= \begin{cases}1 & \text { if } \llbracket \phi \rrbracket(w)=1 \\
0 & \text { if } \llbracket \phi \rrbracket(w)=0 \text { or } \llbracket \phi \rrbracket(w)=\#\end{cases}
\end{aligned}
$$

Footnote 29 continued

quite high. One possibility in order to reconcile our account with the observation that even a sentence like (ii) can trigger an scalar implicature is that there is a general pressure for some to have non-trivial effects with respect to some scalar mechanism, and it could be $\mathrm{EXH}^{2}$ or the PIP. This accounts for the asymmetry between (ii) and (71). In (71), some is responsible for a presupposed ignorance inference, but this is not an option in (ii). For (ii), some can give rise to a non-trivial scalar inference only if $\mathrm{EXH}^{2}$ is present. We thank Raj Singh (p.c.) for helpful discussion related to this point. 
Simply put, $\mathcal{A}$ turns the presuppositions of $\phi$ into part of the assertion, by treating \# as false.

Using the $\mathcal{A}$-operator, we can derive the disjunctive reading by analyzing the sentences in question as (74).

$\left\{\right.$ only, $\left.\mathrm{EXH}^{2}\right\} \mathcal{A}$ he is aware that SOME of the students smoke.

Due to the $\mathcal{A}$-operator, the prejacent now has no presupposition, and synonymous with 'Some of the students smoke and John is aware of that'. Since the alternative ' $\mathcal{A}$ John is aware that all of the students smoke' is stronger than the prejacent, it gets negated, yielding a scalar implicature to the effect that it is not the case that all of the students smoke and John is aware of that, or equivalently, either [not all of the students smoke] or [all of the students smoke but John is not aware of that]. This is exactly what we wanted.

Furthermore, this analysis makes predictions about the availability of such disjunctive inferences. That is, as assumed by many authors, local accommodation is generally a marked option and is facilitated by contextual factors (Beaver and Zeevat 2007; Kadmon 2001). Although it is well beyond the scope of the present paper to elucidate what factors actually matter in licensing local accommodation (which in our opinion are not well understood; see Stalnaker 1974; Simons 2001 for relevant discussion), the context given in (39) seems to be one that favors local accommodation. Consider the following example:

(75) CONTEXT: We know that at least some of the students smoke, and are wondering whether all do.

A: Maybe John knows about the students' smoking habits.

$\mathrm{B}$ : He is not aware that all of the students smoke.

In this context we understand the sentence in (75) as not suggesting that all of the students smoke. We can capture this with the assumption that the use of the $\mathcal{A}$-operator under negation is licensed, i.e.

(76) He is not $\mathcal{A}$ aware that all of the students smoke.

This sentence is predicted to have a disjunctive reading that either not all of the students smoke or they do but John is unaware of that, which complies with the meaning of (75-B) that we intuitively obtain.

Conversely, we expect that when the use of the $\mathcal{A}$-operator is made hard for independent reasons, it should become harder to obtain a disjunctive reading. This is testable given the observation that local accommodation is easier with certain presupposition triggers than others. For instance, the factive presupposition of aware is relatively easy to locally accommodate, while the modal presupposition of the implicative verb remember is harder to locally accommodate. To see this, consider first the following examples containing aware.

(77) a. John is not aware that it's raining, because it's not raining.

b. If John is aware that it's raining, he would probably not go out, but it's probably not raining. 
In order for these sentences to be coherent, the factive presuppositions need to be locally accommodated under not and if respectively. These readings are paraphrased by the following sentences.

(78) a. It is not the case that it is raining and John is aware of that, because it's not raining.

b. If it is raining and John is aware of that, he would probably not go out, but it is probably not raining.

On the other hand, the modal presupposition of remember is much harder, as demonstrated below. We assume that ' $a$ remembered to $P$ ' presupposes that $a$ was required or supposed to do $P$ (Karttunen 1971).

a. \#John didn't remember to call Mary, because he didn't have to.

b. \#If John remembers to read this book, I will not read it, but he probably doesn't have to read it.

These sentences sound contradictory, which indicates that they do not readily admit readings paraphrased by (80).

(80) a. It is not the case that John had to call Mary and he remembered to do so, because he didn't have to.

b. If John has to read this book and remembers to do so, I will not read it, but he probably doesn't have to read it.

Given this contrast between aware and remember, we expect that disjunctive readings to be less prominent with the modal presupposition of remember, and the presuppositions of the non-weaker alternatives to project up. This indeed seems to be the case. Let us consider the following sentences.

a. EXH ${ }^{2}$ John remembered to do a FEW push-ups.

b. John only remembered to do a FEW push-ups.

We assume that the scale involved here is 〈a few, many $\rangle$. Then, the relevant alternative to the prejacent is 'John remembered to do many push-ups. ${ }^{30}$

As we expect, in a context where it is known that John had to do many push-ups, we obtain a scalar inference that John didn't do enough push-ups, as demonstrated by the following examples.

(82) CONTEXT: We know that John has a workout menu he has to do every day, including many push-ups.

\footnotetext{
30 We use the scale 〈a few, many here to avoid potential wide scope readings with some. For instance, (i) allows a wide scope reading of some of the homework.

(i) John remember to do some of the homework.

Under the wide scope reading that some of the homework is such that John remembered to do it, the scalar item takes scope over the presupposition trigger.
} 
A: John has been a bit forgetful these days, and doesn't do all the workout he has to do. Do you know how many push-ups he did today?

B: Today, he remembered to do a FEW push-ups.

$\mathrm{B}^{\prime}$ : Today, he only remembered to do a FEW push-ups.

It is crucial that while aware allows a disjunctive reading in contexts like (39), a comparable reading is much harder to obtain with remember. Consider the following example.

CONTEXT: We know that John has a workout menu he has to do every day, but we do not know how many push-ups John must do. Maybe many, maybe just a few.

A : John has been a bit forgetful these days, and doesn't do all the workout he has to do. Do you know if he did enough push-ups today?

B: ??Today, John remembered to do a FEW push-ups.

B': ??Today, John only remembered to do a FEW push-ups.

As indicated by the question marks, $(83-\mathrm{B})$ and $\left(83-\mathrm{B}^{\prime}\right)$ do not allow a disjunctive reading suggesting that either [John did not have to do many push-ups] or [John had to do many but did only a few], which these sentences would mean with local accommodation. Rather, they seem to trigger an inference that B and B' are implying that John had to do many push-ups, which causes the anomaly. ${ }^{31}$

\section{Tying up loose ends}

We hope to have convinced the reader that the interactions of presuppositions and scalar implicatures motivate two different mechanisms of scalar strengthening, EXH ${ }^{2}$ and the PIP. There are however a number of puzzles and problems, specifically with the PIP. In this section, we address four such puzzles. The first two puzzles, we believe, are not particularly hard to solve, and we suggest ways of addressing them. The last two puzzles necessitate further research and maybe modifications of our proposal.

\subsection{Existential presuppositions}

A potential problem for the PIP concerns sentences with existential presuppositions. Consider for instance:

(84) John is unaware that there are students who solved some of the problems.

As before, we are not interested in the wide scope reading of some or the local scalar implicature reading (whose existence we are not committed to), which would have weaker truth-conditions. The relevant assertive reading of (84) is that John has no belief about any students having solved any of the problems.

\footnotetext{
31 Although we do not deny the possibility of global accommodation of this presupposition, it is perhaps not felicitous in this particular context, as this information is part of the main topic of the conversation. See Beaver and Zeevat (2007), von Fintel (2008) and Stalnaker (1998, 2002) for relevant discussion.
} 
The relevant alternative to the sentence is (85).

John is unaware that there are students who solved all of the problems.

The presupposition of this alternative being stronger, we derive the presupposed ignorance inference that it is not commonly known that there are students who solved all of the problems. However, this seems to be an incorrect result, as (84) is perfectly felicitous (under the relevant reading) in contexts where it is known that some students solved all of the problems (provided there are also students who solved some but not all of the problems).

A similar problem arises with (86-a) and potentially for (86-b), assuming that the and every trigger existential presuppositions.

(86) a. The students who solved some of the problems passed.

b. Every student who solved some of the problems passed.

These sentences presuppose that there are students who solved at least some of the problems. Their alternatives in (87), then, presuppose that there are students who solved all of the problems.

a. The students who solved all of the problems passed.

b. Every student who solved all of the problems passed.

Then, the PIP introduces a presupposed ignorance inference that there are no students who solved all of the problems. This, however, is too strong. Both sentences in (86) are perfectly felicitous in contexts where it is known that some students solved all of the problems, provided that there are also students who solved some but not all of the problems.

In these cases, what seems to be going on is that the assertion and the presupposed ignorance inference are about the same set of individuals. For example, (84) presupposes the existence of students who solved at least some of the problems, and the presupposed ignorance inference says that it is not commonly known that all of these students solved all of the problems. Similarly for (86).

We do not provide a concrete way of solving the present issue (see Geurts 2008, 2009; Sudo 2016 for ideas), but suffice it to say that this is likely to be part of a general problem for inferences based on alternatives. That is, as Geurts $(2008,2009)$ observes, similar problems seem to arise with pure scalar implicatures. For instance, (88) does not seem to have an implicature that there is no student who solved all of the problems.

There are students who solved some of the problems.

Geurts (2008, 2009) and Sudo (2016) propose that the alternatives to such sentences do not involve existential quantifiers but anaphoric terms that are dynamically bound by the existential quantifier in the prejacent. As far as we can see, we could adopt this idea to solve the present puzzle, although we do not provide an explicit proposal here. 


\subsection{The PIP and local contexts}

As pointed out to us independently by an anonymous reviewer, Jacopo Romoli (p.c.) and Clemens Mayr (p.c.), the PIP as stated in this paper fails to account for the following contrasts:

a. Mary will go to Yale or Harvard and John, too, will go to Yale or Harvard b. \#Mary will go to Yale, and John, too, will go to Yale or Harvard

a. If Mary goes to Yale or Harvard, John, too, will go to Yale or Harvard.

b. \#If Mary goes to Yale, John, too, will go to Yale or Harvard.

In both (89-b) and (90-b), the sentence as a whole has no presupposition that can be linked to the word too: the presupposition of too in the second clause is satisfied by the first clause, which provides an antecedent for too with the right property. Now, importantly, the alternatives of these sentences (where Yale or Harvard is replaced with just Yale or with just Harvard) themselves have no presupposition connected to too (again, the presupposition triggered by too is satisfied by the first clause). As a result, the PIP is trivially satisfied, and fails to rule out (89-b) and (90-b).

Now, one standard way to account for the disappearance of these presuppositions consists in introducing a notion of local context for embedded clauses, whereby in both these cases the local context of the second clause is not the common ground, but rather the common ground updated with the first clause (Heim 1983; Beaver 2001; Schlenker 2009), where updating the common ground with a proposition means, in first approximation, conjoining it with the proposition in question. Presuppositions are then defined as conditions on local contexts rather than on the common ground: the presupposition of a clause (or any expression that 'ends in $t$ ') must be entailed not necessarily by the common ground, but by its 'local context'. What happens in (89-b), for example, is that whatever the common ground is, when it is updated with the first conjunct ('Mary will go to Yale or Harvard'), the resulting local context entails the presupposition of the second conjunct - so that the sentence as whole does not impose any specific condition on the initial common ground.

In order to capture the infelicity of (89-b) and (90-b), we can relativize the PIP itself to local contexts, following a proposal made by Singh in relation with a similar problem for Maximize Presupposition (Singh 2011), originally pointed out in Percus (2006). ${ }^{32}$ That is, the PIP would not apply globally to these sentences, but only to the second clause, and would be checked with respect to the common ground updated with the first clause. For instance, what happens with (89-b) is the following. The second clause, John, too, will go to Yale or Harvard, presupposes that Mary will go to Yale

\footnotetext{
32 We have so far assumed a static trivalent semantics, but there is no incompatibility between dynamic semantics and trivalence. In fact, dynamic approaches to presupposition such as Heim (1983) are a form of trivalent semantics (because they crucially rely on the fact that context change potentials are partial functions). Furthermore, it is possible to reconstruct a notion of local context in a static trivalent approach, somewhat similarly to the way Schlenker (2009) reconstructs a notion of local context within a static bivalent approach: the local context of an occurrence of an expression $\phi$ in a sentence $S[\phi]$ with respect to the context set $c$ (a set of possible worlds) is the smallest subset $c^{\prime}$ of $c$ such that if that occurrence of $\phi$ in $S$ is replaced with an expression $\psi$ that never denotes \# in the possible worlds of $c^{\prime}$ and denotes \# in all other possible worlds, the resulting sentence $S[\psi]$ denotes \# in no possible world in $c$.
} 
or Harvard (assuming that the antecedent is determined to be Mary). The alternatives of the second clause, namely John, too, will go to Yale/will go to Harvard, both have a stronger presupposition, namely Mary will go to Yale/will go to Harvard, which is satisfied by the first clause, hence by the local context of the second clause. This would violate the modified, dynamic, version of the PIP, as sketched in (91):

(91) Dynamic PIP (sketch):

Let $S$ be a clause in a given sentence, whose local context is $C_{S}$. Suppose that $S$ presupposes $p$. Let $S^{\prime}$ be an alternative of $S$, with presupposition $p^{\prime}$. If $p^{\prime}$ asymmetrically entails $p$, and if $C_{S}$ entails $p^{\prime}$, then $S$ is infelicitous.

\subsection{Triggers with both positive and negative presuppositions}

A potential problem for the PIP arises with presupposition triggers like discover that have both positive and negative presuppositions. ${ }^{33}$ For instance, (92) presupposes that the complement clause is true and also that John did not know it.

(92) John discovered that Mary was pregnant.

Now take (93). As before, we focus on the surface scope reading here (and also ignore the potentially available local scalar implicature reading).

(93) John discovered that some of the students cheated.

The conjunction of the positive and negative presuppositions creates a non-monotonic presupposition. Thus, the presupposition of the alternative sentence (94) does not entail and is not entailed by the presupposition of (93).

(94) John discovered that all of the students cheated.

What are our predictions here? Suppose a stress falls on some in (93) and hence $\mathrm{EXH}^{2}$ is present. Observe that (94) Strawson-entails (93). Then, it is predicted that $\mathrm{EXH}^{2}$ introduces the negation of (94) together with its presupposition (which also bleeds the PIP). Thus, with a stress on some, (93) is predicted to presuppose the following:

a. All of the students cheated.

b. John did not know that any of the students cheated.

This seems to be a good prediction. The prediction is the same for the version of the sentence with an overt only, which might be easier to judge.

(96) John only discovered that SOME of the students cheated.

Now consider the parse of (93) without $\mathrm{EXH}^{2}$. That is, some is not stressed. Then, the PIP predicts no inference, because the alternative in (94) does not have a stronger

$\overline{33}$ We thank Andreea Nicolae (p.c.) for drawing our attention to this issue. 
presupposition. Rather, the presuppositions of the two sentences are independent from each other.

However, this is a bad prediction, as (93) without a stress on some is as infelicitous as (97) in contexts where it is commonly known that all of the students cheated.

(97) John is unaware that some of the students cheated.

The intuitions become sharper with an example like the following.

(98) \#JOHN discovered that some of the languages have pronouns.

The following modification to the PIP solves the problem.

(99) Let $\phi$ be a sentence presupposing $p$. If $\phi$ has an alternative $\psi$ presupposing $q$ and $q$ is not weaker than $p, \phi$ is infelicitous in context $c$ if $q$ is satisfied in $c$, i.e. $C K_{c}(q)$.

With this, the presupposition of the alternative (94) now matters. That is, the predicted inference for (93) is (100).

(100) $\neg C K$ (all of the students cheated and John did not believe that all of the students cheated)

Now, if the presupposition of the prejacent is satisfied, we have $C K$ (some of the students cheated and John did not believe that some of the students cheated). Since this entails CK(John did not believe that all of the students cheated), the only way (100) can be satisfied together with the presupposition of the prejacent is if (101) is true, which was the desired result.

(101) $\neg C K$ (all of the students)

Unfortunately, this strengthening of the PIP leads to an incorrect prediction for a sentence such as (94), repeated below in (102):

(102) John discovered that all of the students cheated.

This is a case where a strong scalar item occurs in a Strawson-increasing context, so applying $\mathrm{EXH}^{2}$ with focus on all will be a vacuous move. As to the modified version of the PIP, note that the presupposition of the alternative with some is logically independent of the presupposition of (102). The modified PIP thus predicts the following the following felicity condition for (102):

(103) $\neg C K$ (some of the students cheated and John did not believe that some of the students cheated)

Together with the presupposition of the prejacent (i.e. (103)), this reduces to $\neg C K$ (John did not believe that some of the students cheated). (102) is thus predicted to be infelicitous if it is common knowledge that John's past epistemic state was one where he falsely believed that none of the students cheated. This, however, is not a correct pre- 
diction, as the following is perfectly natural (with the suggested prosodic prominence on all):

(104) John believed that none of the students cheated. But then he discovered that ALL of the students cheated.

To conclude, either we maintain our official version of the PIP, but then we fail to account for the perceived presupposed ignorance inference triggered by (98), or we modify the PIP along the lines of (99), but then we make an undesirable prediction for (102). We leave this puzzle unsolved.

\subsection{More on the interactions between EXH and presupposed ignorance}

In the discussion of presupposed ignorance in the previous section, we concentrated on the presupposed ignorance inferences, e.g. for our example (4), we only discussed the inferences that $\neg C K$ (Mary will go to Yale) and $\neg C K$ (Mary will go to Harvard).

(4) Mary will go to Yale. \#John, too, will go to Yale or Harvard.

However, there is one more inference to be accounted for here, i.e. the scalar implicature that Mary will not go to both Yale and Harvard. For this particular example, this inference is contextually excluded anyway, on the assumption that each person will only go to one school, but it is clearly there for sentences like the following, as the contrast in (106) illustrates.

(105) John, too, speaks Japanese or French.

(106) a. Mary speaks Japanese but not French. \#John, too, speaks Japanese or French.

b. Mary speaks Japanese or French. John, too, speaks Japanese or French.

Now, under our theory, there is a parse for (105) which is able to generate both the exclusive reading of disjunction and the presupposed ignorance effect as illustrated in (106). This parse is the following:

too $\mathrm{EXH}^{2}$ John speaks Japanese or French.

In this case, the alternatives to $\mathrm{EXH}^{2}$ have no presuppositions, and $\mathrm{ExH}^{2}$ simply introduces the inference that John does not speak both Japanese and French, based on the conjunctive alternative, which is the only innocently excludable one here. Then, too introduces the presupposition that the antecedent speaks Japanese or French but not both. On top of this, the PIP introduces the following inferences. The relevant alternatives are also indicated in (108).

$$
\begin{aligned}
& \text { a. } \neg C K \text { (Mary speaks Japanese but not French) } \\
& \text { based on 'too EXH John speaks Japanese' } \\
& \text { b. } \neg C K \text { (Mary speaks French but not Japanese) } \\
& \text { based on 'too EXH John speaks French' }
\end{aligned}
$$




\section{c. $\neg C K$ (Mary speaks Japanese and French) based on 'too EXH John speaks Japanese and French'}

With these inferences, we correctly rule in (106-b) and rule out (106-a), as well as (109) below, while accounting for the scalar implicature that John does not speak both languages.

(109) \#Mary speaks both Japanese and French. John, too, speaks Japanese or French.

While this is a good result, there is in principle an alternative parse for (105), in which $\mathrm{EXH}^{2}$ outscopes too, as in (110):

$\mathrm{EXH}^{2}$ (too (John speaks Japanese or French)).

Importantly, according to our analysis, an application of $\mathrm{EXH}^{2}$ above at the top-most level adds to the prejacent the strong negation of (111):

John, too, speaks Japanese and French.

The strong negation of (111) amounts to a) the proposition that John does not speak both Japanese and French, but b) also the presupposition of (111), which is simply (in a context where Mary serves as the antecedent for too) that Mary speaks Japanese and French. Under this parse, then, (105) presupposes that Mary speaks both Japanese and French. This is quite clearly a wrong result. Note, in particular, that (109) is predicted to be felicitous under the parse in (110)

On top of this, the PIP will be vacuous in this case, because the relevant alternatives, which look like the following, all presuppose the same thing as (110), namely that Mary speaks both Japanese and French (this is so because EXH ${ }^{2}$ outscopes too in the alternatives as well, and so the whole structure inherits the presuppositions of the alternatives of the alternatives...).
a. $\mathrm{EXH}^{2}$ John, too, speaks Japanese
b. EXH ${ }^{2}$ John, too, speaks French
c. $\mathrm{EXH}^{2}$ John, too, speaks Japanese and French

What happens here is that the potential effects of the PIP are neutralized by the application $\mathrm{EXH}^{2}$, before, so to speak, the PIP kicks in. A similar logic was at play in Sect. 5.3, as we discussed in connection with (65), but while the neutralization of the PIP by EXH ${ }^{2}$ leads to a correct prediction in the case of (65), this is not so here.

Now, one may think that the problem may be solved (stipulatively) by ruling out a parse such as (110). One might try to capitalize on the fact that the relevant parses involve two focus-sensitive operators ( too and $\mathrm{EXH}^{2}$ ), and that certain constraints about multiple association with focus might help us ruling out the offending parse. Such a strategy, however, is unlikely to succeed, because parses that are entirely parallel to (110) seem to be needed when the disjunction is replaced with some other scalar items. Thus consider the following:

(113) Mary solved all of the problems. John, too, solved most of them. 
The point to be made, here, is that the discourse in (113) is felicitous, and, furthemore, licenses the scalar implicature that John, in contrast with Mary, didn't solve all of the problems. Likewise, the discourse in (114) is felicitous as well, and licenses the scalar implicature that it is not freezing in Paris.

(114) It's freezing in New York. It's cold in Paris, too.

In the absence of $\mathrm{EXH}^{2}$, the PIP would predict both (113) and (114) to be infelicitous. But under parses such as in (115), the second sentences are both predicted to presuppose the first sentences while at the same time generating the observed scalar implicature, which accounts for the observation that both discourses are felicitous:

a. $\operatorname{EXH}^{2}$ (too (John solved most of the problems)).

b. $\mathrm{EXH}^{2}$ (too (It's cold in Paris)).

That being said, these parses not only make the discourses in (113) and (114) felicitous, they also generate very strong presuppositions for the second sentences of these discourses (namely, that Mary solved all of the problems, and that it's freezing in New York), for which we don't seem to have any evidence.

To conclude, the interactions of $\mathrm{EXH}^{2}$, too and various scalar items give rise to significant complications that we do not fully understand. We leave this problem to future research.

\section{Conclusions}

In the present paper we have uncovered a number of empirical facts concerning the interactions between scalar implicatures and presuppositions. In particular, the following three observations had not been given enough attention previously.

- Asymmetry between Strawson-increasing and Strawson-decreasing contexts

- The interaction of prosody and monotonicity and the notion of vacuity based on Strawson-entailment

- Presupposed ignorance inferences

In order to account for these observations, we postulated two scalar strengthening mechanisms. One is the Presupposed Ignorance Principle (PIP), which explains the third observation above. We claimed that Gajewski and Sharvit's observation about Strawson-decreasing cases is explained by this principle as well. In order to account for the first two points, we posited an exhaustivity operator, $\mathrm{EXH}^{2}$ within a trivalent framework in which excludable alternatives are strongly negated, and where the relevant notion of logical strength is Strawson-entailment. The resulting account, we claimed, is empirically superior to the account proposed in Sharvit and Gajewski (2008) and Gajewski and Sharvit (2012) as well as to the account based on $\mathrm{EXH}^{1}$, a different version of EXH that is based on the weak negation and strict entailment.

We can sum up the patterns predicted by our proposal as follows:

- When a low scalar item occurs in a Strawson-increasing context, the scalar item can be stressed and serve as a focus-associate for $\mathrm{EXH}^{2}$, and the resulting structure 
both inherits the presupposition of the alternatives (if any), and gives rise to a scalar implicature. If local accommodation takes place under $\mathrm{EXH}^{2}$, the effect of $\mathrm{EXH}^{2}$ is significantly weakened.

- When a low scalar item occurs in a Strawson-increasing context, under the scope of a presuppositional trigger, but is not focussed (and is not part of a focussed constituent), the PIP is not neutralized, and so the sentence is felicitous only if the common ground does not entail the presupposition of alternatives, when these presuppositions are stronger than that of the prejacent

- When a low scalar item occurs in a Strawson-decreasing, environment, it cannot be stressed (or if so, only for reasons independent of exhaustification), and the PIP kicks in, and so the sentence is felicitous only if the common ground does not entail the presuppositions of the relevant alternatives, when these presuppositions are stronger than that of the prejacent (which accounts for Gajewski and Sharvit's observation about such cases).

Lastly, we woud like to note that we did not discuss the extent to which our account necessitates a grammatical, non-pragmatic approach to scalar implicatures. We view our contribution in this paper as mostly orthogonal to the grammar vs. pragmatics debate. Although we formulated our account using $\mathrm{ExH}^{2}$, it should be noted that in most of our representative examples, $\mathrm{ExH}^{2}$ is applied at a global level, which might make it possible to reformulate our account in pragmatic, inferential terms. One important exception is the data discussed in Sect. 6.4, which appear to require embedding of $\mathrm{EXH}^{2}$ under too. As to the PIP, it is unclear to us whether it can be derived as a pragmatic principle, but we can at least say that such a derivation would certainly not be obvious. ${ }^{34}$

Open Access This article is distributed under the terms of the Creative Commons Attribution 4.0 International License (http://creativecommons.org/licenses/by/4.0/), which permits unrestricted use, distribution, and reproduction in any medium, provided you give appropriate credit to the original author(s) and the source, provide a link to the Creative Commons license, and indicate if changes were made.

\section{Appendix: Maximize Presupposition}

In Sect. 4, we mentioned presuppositional requirements that $\neg C K_{c}(p)$, which are often called anti-presuppositions. Many claim that certain kinds of anti-presuppositions are derived via the principle of Maximize Presupposition (MP) (Heim 1991; Percus 2006; Sauerland 2008; Singh 2011; Schlenker 2012). In the present Appendix, we show that MP alone does not explain the inference Gajewski and Sharvit observe for (2), as they themselves remark in a footnote.

MP is a principle that refers to the presuppositions of the alternatives of a given sentence $\phi$. The idea is that if there is an alternative $\psi$ that makes the same assertive

\footnotetext{
34 Note that in Sect. 6.2, the PIP needed to be relativized to local contexts, but that a pragmatic reconstruction of the notion of local contexts has been offered in Schlenker (2009), and that Schlenker (2012) is an attempt to derive Maximize Presupposition effects, which can be viewed as special cases of the PIP (see Appendix) as pragmatic effects.
} 
claim as $\phi$ and has a stronger presupposition than $\phi, \psi$ is preferred. As a consequence, the use of $\phi$ triggers an inference that $\psi$ could not have been used. Here is a version of the principle. ${ }^{35}$

\section{MAXIMIZE PRESUPPOSITION}

If the following is true for any $\psi \in A L T(\phi)$, sentence $\phi$ cannot be felicitously asserted in context $c$ :

a. The presupposition of $\psi$ asymmetrically entails the presupposition of $\phi$ and;

b. $\phi$ and $\psi$ are contextually equivalent.

For instance, MP explains the scalar inference of the sentence in (117), understood as meaning the students who did at least some of the homework passed, and presupposing that there are students who did some but not all of the homework.

(117) The students who did some of the homework passed.

Notice that the presupposition triggered by the definite article should be merely that there are students who did some of the homework, which does not exclude the possibility that they actually did all. The observed presupposition is derived via MP as follows. Assume that (118) is an alternative of (117):

The students who did all of the homework passed.

This alternative presupposes that there are students who did all of the homework, and this presupposition entails that of (117). Therefore, according to MP, (117) is infelicitous if it is contextually equivalent to (118). When are these sentences contextually equivalent? They are contextually equivalent if it is commonly known that every student who did some of the homework in fact did all of it. Therefore, (117) is felicitous only if it is not commonly known that every student who did some of the homework did all of it, i.e. it is not commonly known that no student did some but not all of the homework. As mentioned in passing in Sect. 5.2, with Chemla's (2008) Epistemic Step for Anti-Presupposition, we can derive a stronger inference from this that some of the relevant students did not do all of the homework.

However, MP does not explain Gajewski and Sharvit's observation that (2) appears to presuppose that not all of the students smoke.

(2) John is unaware that some of the students smoke.

The relevant alternative is (119).

(119) John is unaware that all of the students smoke.

This alternative presupposes that all of the students smoke, and this presupposition entails the presupposition of (2). Thus, Maximize Presupposition tells us that (2) is

\footnotetext{
35 This version runs into a 'projection problem', as pointed out by Percus (2006) (see also Singh 2011). For the sake of simplicity, we will ignore this complication, but a solution could be given using local contexts, as Singh (2011) claims. See related discussion in Sect. 6.2.
} 
infelicitous if it is contextually equivalent to (119). However, there are situations where the presupposition of (119) is satisfied and yet (2) and (119) are not contextually equivalent. Consider the following context: it is commonly known that all of the students smoke, and thus the presuppositions of the sentences are satisfied. Now, suppose that there are the following three sets of possible worlds in the context set: In some possible worlds $W_{1}$, John is aware that some of the students smoke but is not aware that all do; In some other possible worlds $W_{2}$, John is aware that all of the students smoke; In yet another possible worlds $W_{3}$, John is not aware that any of the students smoke. Now notice that (2) is true in worlds $W_{3}$, but (119) is true in both worlds $W_{1}$ and $W_{3}$. Consequently, in such a context, (2) and (119) are not contextually equivalent, and MP fails to generate the inference that it is not common knowledge that all of the students came.

One could see our PIP as a generalization of MP, as the PIP is essentially MP without the requirement on the contextual equivalence between $\phi$ and $\psi$. Thus, it is expected that the PIP explains everything that MP is used to explain. However, having fewer requirements on the relevant alternatives, the PIP relies on the theory of alternatives more heavily than MP. Since the theory of alternatives itself is far from a settled issue (see Horn 1972; Katzir 2007; Breheny et al. 2016 and references therein), we need to leave this issue for future research.

\section{References}

Beaver, D. (2001). Presupposition and assertion in dynamic semantics. Stanford: CSLI.

Beaver, D., \& Krahmer, E. (2001). A partial account of presupposition projection. Journal of Logic, Language, and Information, 10(2), 147-182.

Beaver, D., \& Zeevat, H. (2007). Accommodation. In G. Ramchand \& C. Reiss (Eds.), The Oxford handbook of linguistic interfaces (pp. 503-538). Oxford: Oxford University Press.

Bochvar, D. A. (1981). On a three-valued logical calculus and its application to the analysis of the paradoxes of the classical extended functional calculus. History and Philosophy of Logic2, 87-112. Translated by Merrie Bergmann [Originally published as "Ob odnom trechznacnom iscislenii i ego primenenii $\mathrm{k}$ analizu paradoksov klassiceskogo rassirennogo funkcional'nogo iscislenija. Matematiceskij Sbornik, 4(46), 287-308 (1939).].

Breheny, R., Klinedinst, N., Romoli, J., \& Sudo, Y. (2016). The symmetry problem: Current theories and prospects. London: Ms. University College London and Ulster University.

Büring, D. (2007). The least at least can do. In C. B. Chang \& H. J. Haynie (Eds.), Proceedings of WCCFL 26 (pp. 114-120). Somerville, MA: Cascadilla Proceedings Project.

Chemla, E. (2008). An epistemic step for anti-presuppositions. Journal of Semantics, 25(2), 141-173.

Chemla, E. (2009). Similarity: Towards a unified account of scalar implicatures, free choice permission and presupposition projection. Ms.

Chierchia, G. (2004). Scalar implicatures, polarity phenomena, and the syntax/pragmatics interface. In A. Belletti (Ed.), Structures and beyond: The cartography of syntactic structures (pp. 39-103). Oxford: Oxford University Press.

Chierchia, G. (2006). Broaden your views: Implicatures of domain widening and the "Logicality" of language. Linguistic Inquiry, 37(4), 535-590.

Chierchia, G., Fox, D., \& Spector, B. (2012). Scalar implicature as a grammatical phenomenon. In C. Maienborn, K. von Heusinger, \& P. Portner (Eds.), Semantics: An international handbook of natural language meaning (pp. 2297-2331). Berlin: de Gruyter.

Crnič, L. (2011). Getting even, Ph.D. dissertation, Massachusetts Institute of Technology.

Fox, D. (2007). Free choice and the theory of scalar implicatures. In U. Sauerland \& P. Stateva (Eds.), Presupposition and implicature in compositional semantics (pp. 71-112). New York: Palgrave Macmillan. 
Fox, D. (2008). Two short notes on Schlenker's theory of presupposition projection. Theoretical Linguistics, 34(3), 237-252.

Fox, D., \& Hackl, M. (2006). The universal density of measurement. Linguistics and Philosophy, 29(5), 537-586.

Fox, D., \& Katzir, R. (2011). On the characterization of alternatives. Natural Language Semantics, 19(1), $87-107$.

Gajewski, J. (2011). Licensing strong NPIs. Natural Language Semantics, 19(2), 109-148.

Gajewski, J., \& Sharvit, Y. (2012). In defense of grammatical approach to local implicatures. Natural Language Semantics, 20(1), 31-57.

Gazdar, G. (1979). Pragmatics: Implicature, presupposition, and logical form. New York: Academic Press.

George, B. (2008). A new predictive theory of presupposition projection. Proceedings of SALT, 18, 358-375.

Gettier, E. (1963). Is justified true belief knowledge? Analysis, 23(6), 121-123.

Geurts, B. (2008). Implicture as a discourse phenomenon. Proceedings of Sinn und Bedeutung, 11, 261-275.

Geurts, B. (2009). Scalar implicature and local pragmatics. Mind \& Language, 24(1), 51-79.

Geurts, B. (2010). Quantitiy implicatures. Cambridge: Cambridge University Press.

Groenendijk, J., \& Stokhof, M. (1984). Studies on the semantics of questions and the pragmatics of answers, Ph.D. thesis, University of Amsterdam.

Heim, I. (1983). On the projection problem for presuppositions. In WCCFL 2, pp. 114-125.

Heim, I. (1991). Artikel und Definitheit. In A. von Stechow \& D. Wunderlich (Eds.), Semantik: Ein internationales Handbuch der zeitgenössischen Forschung/Semantics: An International Handbook of Contemporary Research (pp. 487-535). Berlin: de Gruyter.

Horn, L. (1972). On the semantic properties of the logical operators, Ph.D. thesis, University of California Los Angeles.

Horn, L. (1997). Presupposition and implicature. In S. Lappin (Ed.), The handbook of contemporary semantic theory. Oxford: Blackwell.

Ivlieva, N. (2013) Scalar implicatures and the grammar of plurality and disjunction, Ph.D. thesis, Massachusetts Institute of Technology.

Jacobson, P. (2012). The direct compositionality and "uninterpretability": The case of (sometimes) "uninterpretable" features on pronouns. Journal of Semantics, 29(3), 305-343.

Kadmon, N. (2001). Formal pragmatics. Oxford: Blackwell.

Karttunen, L. (1971). Implicative verbs. Language, 47(2), 340-358.

Karttunen, L., \& Peters, S. (1979). Conventional implicature. In C.-K. Oh \& D. Dinneen (Eds.), Syntax and semantics 11: Presupposition (pp. 1-56). New York: Academic Press.

Katzir, R. (2007). Structurally-defined alternatives. Linguistics and Philosophy, 30(6), 669-690.

Mayr, C., \& Romoli, J. (2016). A puzzle for theories of redundancy: Exhaustification, incrementality, and the notion of local context. Semantics and Pragmatics, 9(7), 1-48.

Meyer, M.-C. (2013) Ignorance and grammar, Ph.D. thesis, Massachusetts Institute of Technology.

Percus, O. (2006). Antipresuppositions, Technical report. Report of the Grant-in-Aid for Scientific Research (B), Project No: Japan Society for the Promotion of Science. 15320052.

Peters, S. (1979). A truth-conditional formulation of Karttunen's account of presupposition. Synthese, 40(2), 301-316.

Potts, C. (2008). Wait a minute! What kind of discourse strategy is this? Annotated data. Ms. http:// christopherpotts.net/ling/data/waitaminute/.

Potts, C. (2015). Presupposition and implicature. In S. Lappin \& C. Fox (Eds.), The handbook of contemporary semantic theory (2nd ed., pp. 168-202). Oxford: Wiley-Blackwell.

Romoli, J. (2012). Soft but strong: Neg-raising, soft triggers, and exhaustification, Ph.D. thesis, Harvard University.

Rooth, M. (1985). Association with focus, Ph.D. dissertation, University of Massachusetts, Amherst.

Rooth, M. (1992). A theory of focus interpretation. Natural Language Semantics, 1(1), 75-116.

Rothschild, D. (2011). Explaining presupposition projection with dynamic semantics. Semantics and Pragmatics, 4(3), 1-43.

Rullmann, H. (2003). Additive particles and polarity. Journal of Semantics, 20(4), 329-401.

Russell, B. (2006). Against grammatical computation of scalar implicatures. Journal of Semantics, 23(4), 361-382.

Sauerland, U. (2004). Scalar implicatures in complex sentences. Linguistics and Philosophy, 27(3), 367391. 
Sauerland, U. (2008). Implicated presuppositions. In A. Steube (Ed.), The discourse potential of underspecified structures. Language, context and cognition (pp. 581-600). Berlin: Mouton de Gruyter.

Sauerland, U. (2013). Presuppositions and the alternative tier. In Proceedings of SALT 23, pp. 156-173.

Schlenker, P. (2008). Be Articulate! A pragmatic theory of presupposition projection. Theoretical Linguistics, 34(3), 157-212.

Schlenker, P. (2009). Local contexts. Semantics \& Pragmatics, 2, 1-78.

Schlenker, P. (2012). Maximize presupposition and Gricean reasoning. Natural Language Semantics, 20(4), 391-429.

Schwarz, B. (2016). Consistency preservation in quantifity implicature: The case of at least. Semantics \& Pragmatics, 9(1), 1-47.

Sharvit, Y., \& Gajewski, J. (2008). On the calculation of local implicatures. In WCCFL, Vol. 26, pp. 411-419.

Simons, M. (2001). On the conversational basis of some presuppositions. In Proceedings of semantics and linguistic theory (SALT) (pp. 431-448).

Simons, M. (2006). Notes on the embedded implicatures. Pittsburgh: Ms. Carnegie Mellon University.

Singh, R. (2011). Maximize presupposition! and local contexts. Natural Language Semantics, 19(2), 149168.

Spathas, G. (2010) Focus on anaphora, Ph.D. dissertation, Universiteit Utrecht.

Spector, B. (2003). Scalar implicatures: Exhaustivity and Gricean reasoning. In B. ten Cate (Ed.), Proceedings of the 8th ESSLLI student session, Vienna, pp. 277-288.

Spector, B. (2007). Scalar implicatures: Exhaustivity and Gricean reasoning. In M. Aloni, A. Butler, \& P. Dekker (Eds.), Questions in Dynamic Semantics (pp. 225-249). Emerald: Bingley.

Spector, B. (2014). Global positive polarity items and obligatory exhaustivity. Semantics \& Pragmatics, 7(11), 1-61.

Stalnaker, R. (1974). Pragmatic presuppositions. In M. Munitz \& P. Unger (Eds.), Semantics and Philosophy (pp. 197-213). New York: New York University Press.

Stalnaker, R. (1998). On the representation of context. Journal of Logic, Language and Information, 7, 3-19.

Stalnaker, R. (2002). Common ground. Linguistics and Philosophy, 25(5-6), 701-721.

Sudo, Y. (2012). On the semantics of Phi features on pronouns, Ph.D. dissertation, Massachusetts Institute of Technology.

Sudo, Y. (2016). The existential problem of scalar implicatures and anaphora across alternatives. In C. Piñón (Ed.), Empirical issues in syntax and semantics 11 (pp. 225-244). http://www.cssp.cnrs.fr/ eiss11/index_en.html.

Tonhauser, J., Beaver, D., Roberts, C., \& Simons, M. (2011). Towards a taxonomy of projective content. Ms., Ohio State University, University of Texas, Austin, and Carnegie Mellon University.

van der Sandt, R. (1988). Context and presupposition. London: Croom Helm.

van Rooij, R., \& Schulz, K. (2004). Exhaustive interpretation of complex sentences. Journal of Logic, Language and Information, 13(4), 491-519.

von Fintel, K. (1999). NPI licensing, and context dependency. Journal of Semantics, 16(2), 97-148.

von Fintel, K. (2004). Would you believe it? The king of France is back! (Presuppositions and truth-value intuitions). In M. Reimer \& A. Bezuidenhout (Eds.), Descriptions and beyond (pp. 315-341). Oxford: Oxford University Press.

von Fintel, K. (2008). What is presupposition accomodation, again? Philosophical Perspectives, 22(1), $137-170$.

von Fintel, K., \& Matthewson, L. (2008). Universals in semantics. The Linguistic Review, 25(1-2), 139-201.

Zondervan, A. J. (2010). Scalar implicatures or focus: An experimental approach, Ph.D. thesis, Universiteit Utrecht. 